\title{
ASÍ EN ORIENTE COMO EN OCCIDENTE: EL ORIGEN ORIENTAL DE LOS ALTARES TAURODÉRMICOS DE LA PENÍNSULA IBÉRICA
}

\author{
THUS IN THE EAST AND THE WEST: THE EASTERN ORIGIN OF \\ THE BULL SKIN ALTARS OF THE IBERIAN PENINSULA
}

\author{
ÁLVARO GÓMEZ PEÑA*
}

\begin{abstract}
“ [...] el argumento de que aras con esta forma no se conocen en el Mediterráneo oriental queda de nuevo invalidado si las imágenes de dicho símbolo grabadas sobre algunos sellos chipriotas, que se han leído como lingotes se interpretan en cambio como altares"
\end{abstract}

(Escacena 2007: 628).

\begin{abstract}
Resumen: En las siguientes líneas nos proponemos, en primer lugar, demostrar el origen siriochipriota de los altares taurodérmicos de la protohistoria de la Península Ibérica exponiendo los ejemplos recogidos procedentes del Mediterráneo Oriental y comparando sus contextos con los de los altares en forma de piel de toro del Hierro I hallados hasta la fecha en España; en segundo lugar, demostrar que los tradicionalmente denominados lingotes chipriotas, siriochipriotas para nosotros, no son el motivo que imitan los altares taurodérmicos, sino que ambas ramas son el resultado de un mismo tronco común: la piel de toro trabajada y; por último, recalcar el carácter identitario fenopúnico de los altares taurodérmicos fechables en el Hierro II que han aparecido por toda la costa peninsular ibérica.

Palabras claves: Altares taurodérmicos, lingotes, cilindrossellos, asherah.
\end{abstract}

En los últimos veinte años el descubrimiento de numerosos altares taurodérmicos ha empezado a llenar en parte un vacío en las investigaciones protohistóricas de la Península Ibérica que se antoja de suma

\footnotetext{
* Miembro del Grupo de Investigación Historiografia y $\mathrm{Pa}$ trimonio Andaluz (HUM-402). Consejería de Cultura de la Junta de Andalucía.
}

Abstract: Firstly in the following lines we aim to prove the Sirian-Cypriot origin of the bull-skin-shaped shrines of the Protohistory of the Iberian Peninsula by showing the samples collected from the Eastern Mediterranean and comparing their contexts with the bull-skin-shaped shrines of the Iron Age I found in Spain. Secondly, it will be proven that the traditionally named Cypriot ingots, Sirian-Cypriots for us, are not the motif imitated by the bull-skin-shaped shrines, but both models come from a single one stock: the crafted bull-skin. Finally the identitarian character of the Phoenopunic bull-skin-shaped shrines dated from the Iron Age II that have appeared throughout the Iberian Peninsula coast will be highlighted.

Key words: Bull-skin-shaped shrines, ingots, cylinder-seals, asherah.

importancia para entender la religiosidad fenopúnica. Éstos, presentes en el caso del Hierro I, han aparecido en santuarios de tradición levantina cuyos datos apuntan hacia una continuidad cultual y cultural entre los complejos religiosos del Mediterráneo del Este y los santuarios orientales del Mediterráneo Occidental: thymiateria, huevos de avestruz, conchas, smiting gods, betilos, alabastrinos, cornamentas de animales y así con una larga lista de elementos que tienen sus 
equivalencias al otro lado del posterior Mare Nostrum. ¿Cómo es posible que de todos ellos, los altares no tuvieran sus paralelos orientales? El altar, como objeto que encierra las actuaciones más sagradas de una comunidad religiosa se convierte inmediatamente en la pieza clave en torno a la que giran los rituales de dicho colectivo y, por tanto, en un buen elemento identitario.

\section{DIOSES, LINGOTES Y SELLOS EN LA TRADICIÓN SIRIOCHIPRIOTA}

Recientemente hemos tratado desde un punto de vista historiográfico y metodológico la relación de elementos taurodérmicos hallados en la Península Ibérica (Gómez Peña e. p.), y no nos ha sorprendido comprobar que la inmensa mayoría de los autores que ha trabajado sobre ellos ha seguido la tradicional interpretación que relaciona estas formas con los lingotes "chipriotas", pues efectivamente ambas formas están emparentadas. Sin embargo, dicha interpretación es desde nuestro punto de vista inexacta ya que existe una idea que aglutina a ambas: la taurodérmica. No obstante, hay quienes han pensado que el parecido entre ambos, lingotes y pieles, es puramente casual (Bass 1961: 272; 1986: 275; Pulak 1988: 6, nota a pie 8) ya que el contorno de los primeros se realizó para facilitar su transporte sobre los hombros como se observa en diferentes representaciones (fig. 1). No podemos saber con seguridad si la forma se escogió por su fácil transporte o si aquélla acabó encontrando buen acomodo en los hombros de sus cargadores, pero aun así no es óbice para pensar que su más fácil transporte y su simbolismo sean incompatibles.

El motivo, por tanto, por el que analizaremos aquí los lingotes de forma taurodérmica radica en el estrecho

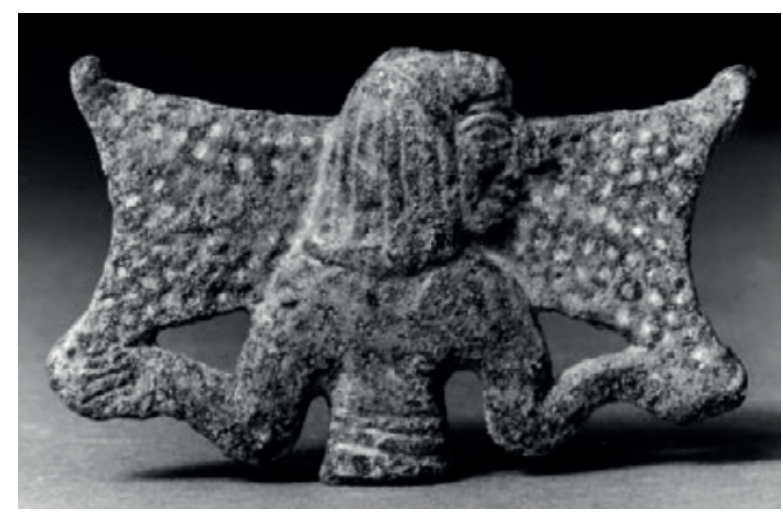

Figura 1. Fragmento de bronce procedente de Chipre mostrando a un hombre portando un lingote sobre sus hombros (Karageorghis y Papasavvas 2001: 340).

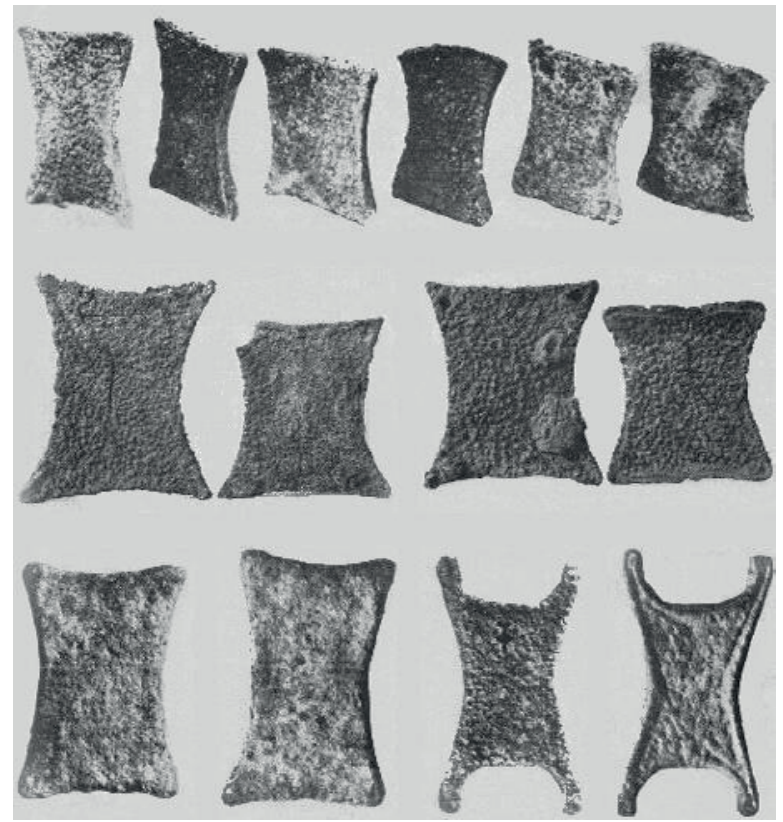

Figura 2. Varios tipos de lingotes de cobre de procedencia oriental paralelizables con los altares de El Carambolo, Caura y Malaka (a partir de Buchholz y Karageorghis 1973: 279).

paralelismo existente entre sus diversas facturas y las de los altares de forma de piel de toro del Suroeste peninsular (fig. 2), proponiéndonos demostrar a partir de aquí el origen siriochipriota tanto de los lingotes, como de esta forma y de su respectiva simbología introducida en occidente.

Siguiendo la metodología expuesta en otra ocasión (Gómez Peña e. p.), son los propios lingotes los que nos indican que en la tradición oriental se conocía el trabajo de la piel bovina con factura idéntica o similar a los ejemplares conocidos en la Península Ibérica. No ya sólo lo evidencia la forma de las piezas, con sus esquinas pronunciadas, sino que algunos ejemplares muestran un doble contorno como los altares de El Carambolo, Caura o Malaka, entre otros. Incluso tenemos representaciones de pieles con este perfil tanto en monturas como la del caballero de Byblos (siglos VIIIVI a. C.) (fig. 3), como en instrumentos musicales visibles en decoraciones de menaje de lujo procedentes de Chipre (fig. 4). Adviértase que en dicho plato aparecen tanto los lingotes como las pieles trabajadas, ambos con idéntica factura. En este último ejemplo tiene fácil lectura la forma de piel de bóvido de los panderos, pero el mayor problema al que nos hemos tenido que enfrentar y que auguramos que de buen seguro dará bastantes quebraderos de cabeza en un futuro es discernir cuándo estamos ante las representaciones de lingotes 


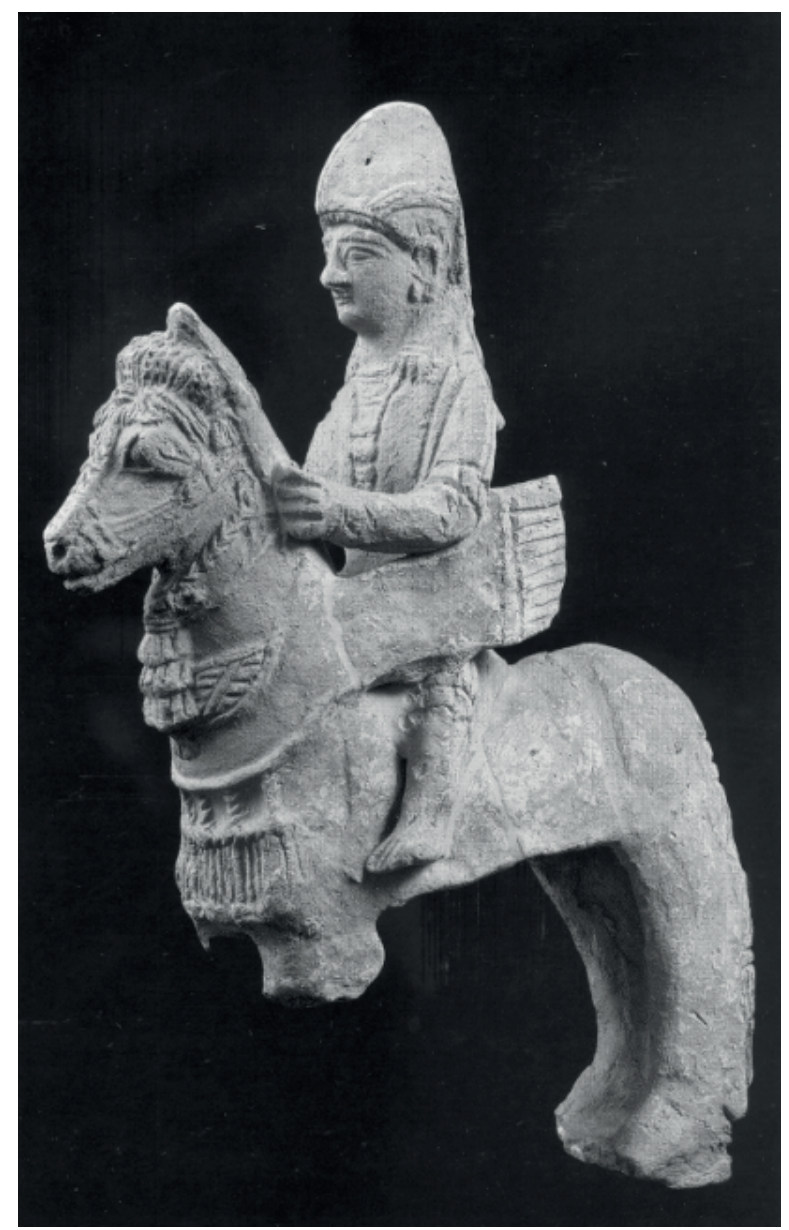

Figura 3. La montura recuerda a los ejemplares de Cancho Roano y El Cigarralejo (según Institut du Monde Arabe 2008: 190).

propiamente dichos y cuándo estamos ante los altares taurodérmicos, porque siguiendo la primera interpretación, todo lo que en Oriente ha tenido este contorno ha sido considerado representación de un lingote. Mucho tienen que ver en esta interpretación los hallazgos de dos pecios durante el siglo XX hundidos frente a las costas de la actual Turquía en los que se encontró entre su cargamento cientos de lingotes con esta forma. No obstante, no fueron los primeros descubrimientos realizados de este tipo de objetos, pues ya H.-G. Buchholz había realizado en 1958 y 1959 dos estudios al respecto intentando ver la evolución formal de los ejemplares en el tiempo (Buchholz 1958 y 1959, en Bass 1961: 271, notas a pie 17, 18 y 19), así como su representación se ha creído ver en cilindros-sellos (Masson 1957, en Bass 1961 , nota a pie 17$)^{1}$.

1. Hasta el presente se ha documentado el hallazgo de lingotes y medios lingotes taurodérmicos, tanto comerciales como votivos, en

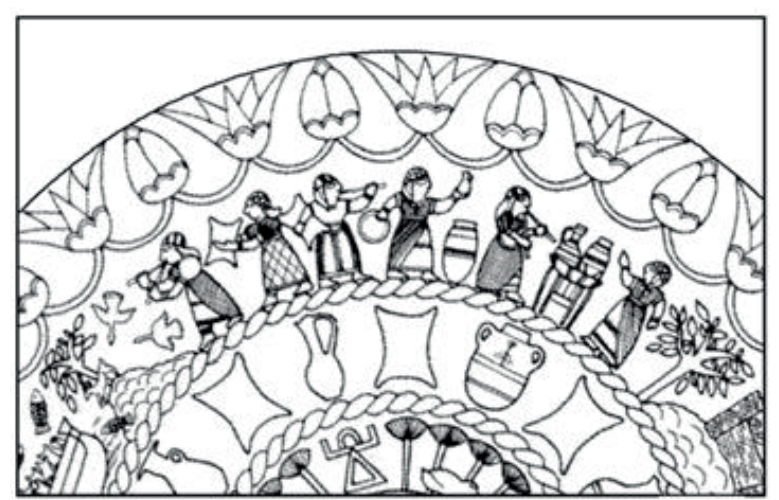

Figura 4. En la imagen se observan lingotes transportados en barcas junto a un cuerpo de música y danza con instrumentos de percusión en forma de piel trabajada (Bikai 1987: portada).

El primero de los barcos encontrados se trata del pecio de Cabo Gelidonya (fig. 5), al suroeste de Turquía, en el que se hallaron 30 lingotes y 10 medios lingotes con forma de piel de toro (Bass 1961: 271). Miden 60 $\mathrm{cm}$ de largo y $45 \mathrm{~cm}$ de ancho, y pesan $20,6 \mathrm{~kg}$ de media. A pesar de ser la parte más numerosa del cargamento, éste apareció compuesto en su gran mayoría por objetos de prestigio que han sido relacionados con el mundo sirio y chipriota. El trasiego de objetos y mercancías entre estas dos partes del Mediterráneo nos hace pensar en que su estrecha vinculación pudo haber sido no sólo comercial. De hecho, G. F. Bass, postuló un origen sirio para el barco, aunque opinaba que los lingotes son de procedencia chipriota (Bass 1991: 69-70).

Justo dos años después, en 1963, se halló en una fosa fundacional de un santuario de Enkomi (Chipre) un smiting god cuyos pies aparecen sobre un objeto considerado tradicionalmente de forma de lingote chipriota (fig. 6). Desde ese momento y hasta el presente ha sido una pieza clave en la historiografía del estudio de los lingotes. Se trata de una estatuilla de $35 \mathrm{~cm}$ de altura que representa a una figura masculina ataviada con un casco con cuernos, barba, camisa con escote en $\mathrm{V}$, falda corta abierta por delante y grebas en sus piernas. Sujeta en su mano izquierda un escudo y en la derecha una lanza en posición hierática. Su hallazgo en

bastantes puntos del Mediterráneo e incluso en zonas de Europa más alejadas del posterior Mare Nostrum. Desde Egipto (Nibbi 1987: 57 90), pasando por Israel (Buchholz 1988: 203-204), Líbano, Chipre (Buchholz 1988: 206), Turquía (Muhly, Wheeler y Maddin 1977; Bass 1986; Pulak 1988), Bulgaria (Buchholz 1988: 204), Croacia, Grecia, Creta (Buchholz 1988: 206-207), Sicilia (Buchholz 1988: 210), Cerdeña (Balmuth y Tylecote 1976), Córcega (Knapp 2008: 131), Alemania (Knapp 2008: 131) e incluso Irlanda (Buchholz 1988; Gale 1991) 


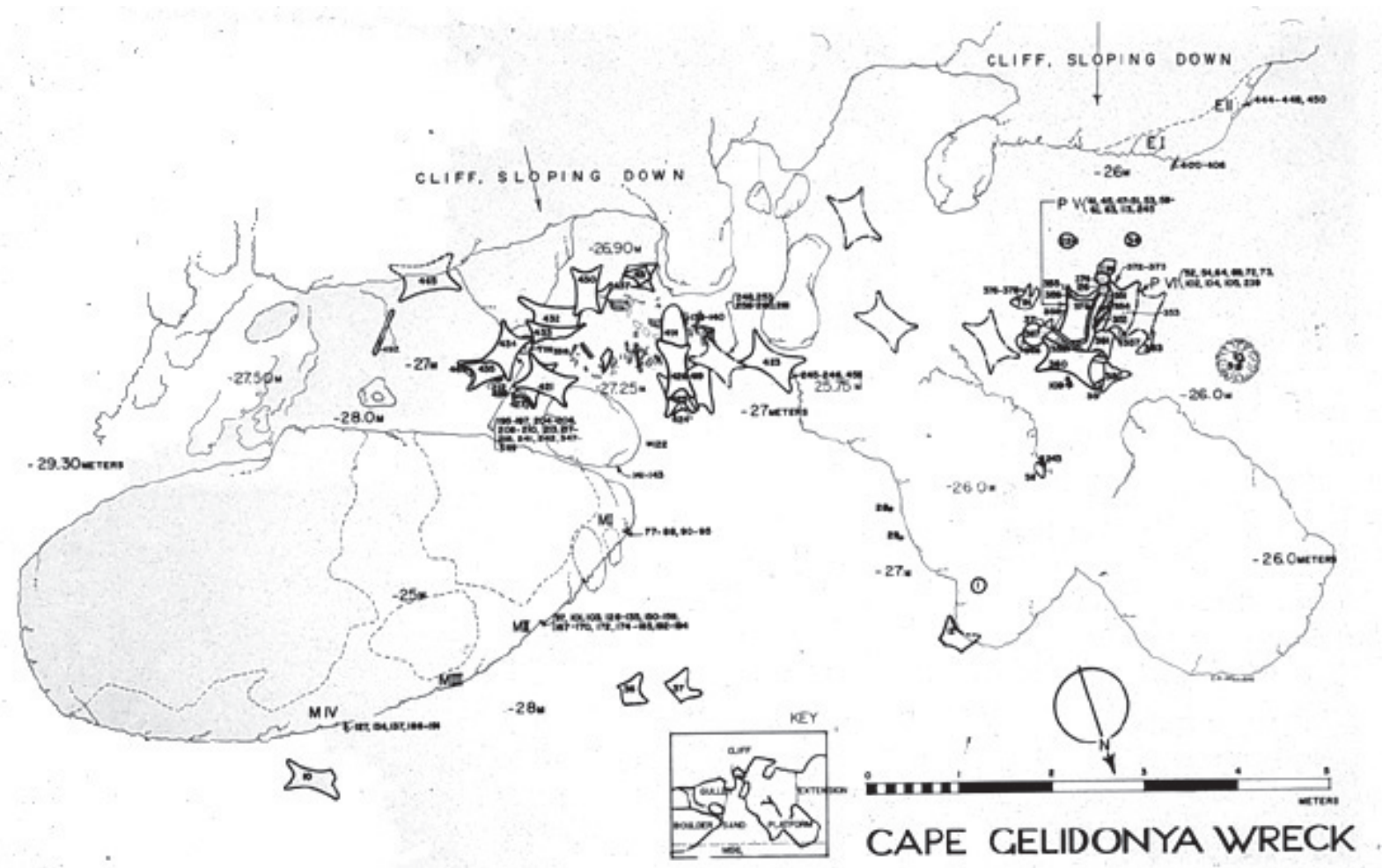

Figura 5. Planta de la situación en que se halló parte del cargamento del pecio de Cabo Gelidonya (web del Institute of Nautical Archaeology).

dicha fosa, excavada en la cella del templo, sacó a la luz no sólo a la estatuilla de pie, sino varios vasos muy probablemente de uso ritual a su alrededor (Schaeffer 1971: 525 y ss.). Por su parte, en el suelo de dicha sala se encontraron restos óseos de diferentes animales entre los que destacan los bucráneos y las cornamentas de toros y de otros bóvidos, así como restos óseos de cérvidos (Schaeffer 1964: 179) que denotan la realización de sacrificios de animales asociados a los altares presentes en la estancia. De igual manera, en otro santuario situado a $50 \mathrm{~m}$ de éste apareció otra figura de pie en una fosa de las mismas características que porta un casco igualmente con cuernos, de ahí que se conozca al templo como el del "dios cornudo" (Schaeffer 1971: 533 y ss.). También aparecieron restos de animales por toda la estancia, entre ellos huesos de ciervos, cabras y especialmente bueyes al parecer cremados y libados. En ambos casos han aparecido en el interior de los santuarios varios lingotes votivos, si bien no es una particularidad de éstos, pues han aparecido igualmente en Egipto entre otros lugares (Buchholz 1988). Relacionada con el "dios del lingote", nombre que designa también al santuario en el que se halló, existe otra figura, esta vez femenina, procedente de la colección
Bomford del Ashmolean Museum de Oxford por presentarse también de pie sobre, según la interpretación tradicional, el mismo tipo de lingote (fig. 7). Su procedencia es desconocida pero por sus características formales se le ha otorgado un origen chipriota (Catling 1971). Las constantes relaciones entre los lingotes y la isla de Chipre han sido motivo para asociar ambas estatuillas por parte de algunos investigadores con divinidades de origen chipriota (Catling 1971; Marín 2006: 45). Ambas estatuillas han sido relacionadas con el culto a una pareja de divinidades, siendo la masculina protectora de los trabajos en las minas de la isla y la femenina garante de la fecundidad de las mismas. La primera de ellas, denominada desde su hallazgo como "el dios del lingote", ha sido identificada con el Nergal babilónico y con el Reshef sirio como dos encarnaciones para una misma fuerza del mundo de los muertos (Schaeffer 1971: 506-510).

El segundo pecio fue hallado en el cabo Ulu Burun, cerca de Kas (Turquía), en 1984. En él, el equipo dirigido por C. Pulak, del Instituto de Arqueología Náutica de Texas, halló un cargamento de clara procedencia siria para la mayoría de las piezas entre el que había 354 lingotes con forma de piel de toro (fig. 8), 


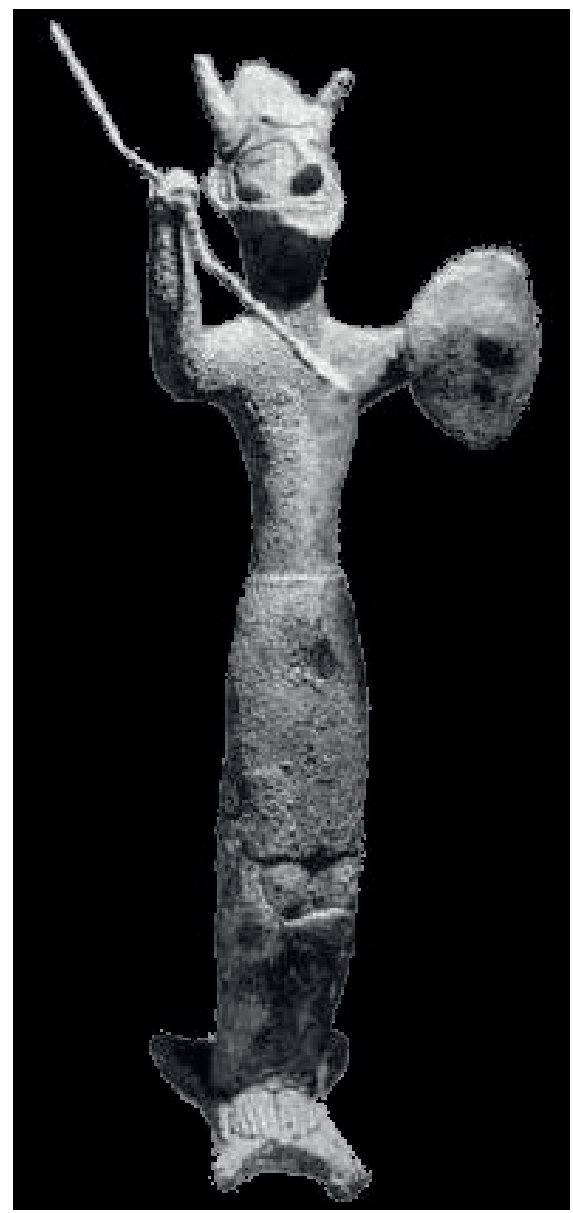

Figura 6. Smiting god masculino del "dios del lingote" representando a una divinidad manifestándose sobre el altar (Celestino 2008: 323-324).

documentándose los primeros de estaño (Bass 1986: 276; Pulak 1988: 4). Acompañando a la ingente cantidad de lingotes de cobre y estaño había colmillos de elefante, ánforas cananeas y vasijas de tradición siria, incienso probablemente procedente de Ugarit, armas cananeas, joyas sirias, pesas cuyos pesos equivalen al sistema sirio, sirio necef, babilónico y peyem, anclas de un sólo orificio igual a las encontradas en Tell Abu Hawam, Ugarit, Biblos, en el pecio de Cabo Gelidonya y en Kition. Todos estos objetos hicieron a G. F. Bass, excavador del pecio de Cabo Gelidonya atribuir una procedencia siria para el cargamento, no así del barco del que no se pronuncia, atribuyendo el origen de los lingotes a la misma zona (Bass 1986: 295) entre otros motivos porque el único molde encontrado hasta aquella fecha (y hasta el presente) ha sido el hallado en Ugarit, como más adelante comentaremos. En

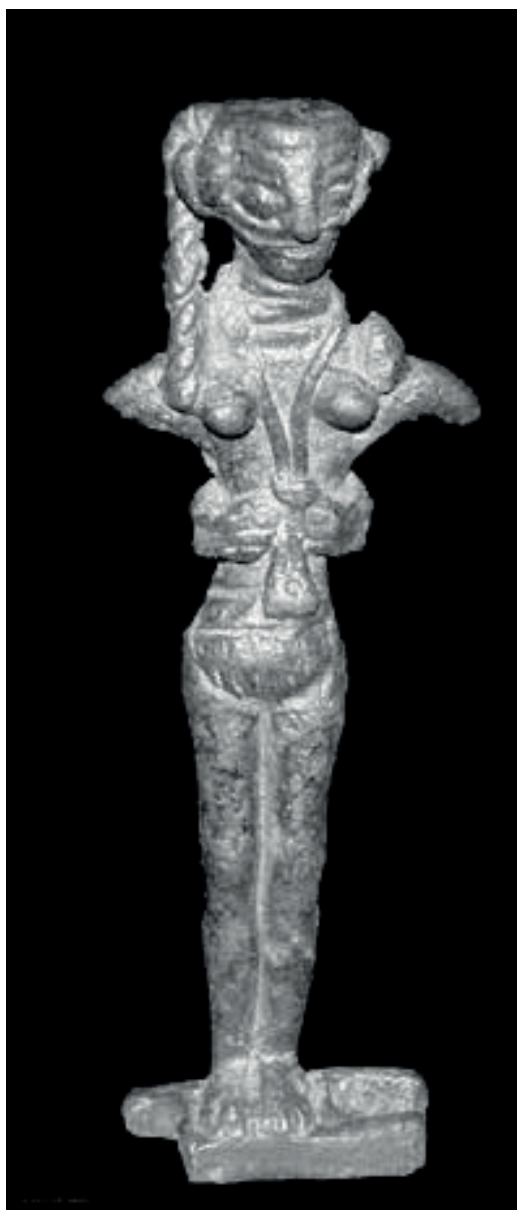

Figura 7. Smiting god femenino de diosa sobre altar. Esta hipótesis es posible gracias a los hallazgos de altares de forma taurodérmica aparecidos en la Península Ibérica (Celestino 2008: 323-324).

cuanto a la procedencia del pecio, posteriores campañas y estudios han posibilitado atribuir también un origen sirio para la forma que dejan entrever los escasos restos encontrados, entre ellos la propia madera de cedro de la que estuvo hecho el barco. A esta hipótesis viene a sumarse la opinión de quienes ven en la mayor parte de los utensilios de uso común el origen de los tripulantes puesto que las herramientas, instrumentos, estatuillas, las citadas anclas, las pesas de balanza y las lámparas de aceite son atribuibles al mundo levantino (cananeo o sirio) (Bass 1989; Pulak 2001: 14 y 49, en Gestoso 2007: 30). Incluso las tablillas de contabilidad, realizadas en madera de boj, de procedencia ugarítica, reafirman esta hipótesis, siendo a nuestro juicio un factor para pensar que la persona encargada de llevar las cuentas en la nave estaba bajo la esfera de influencia ugarítica ya que el tipo de soporte de escritura a base de 


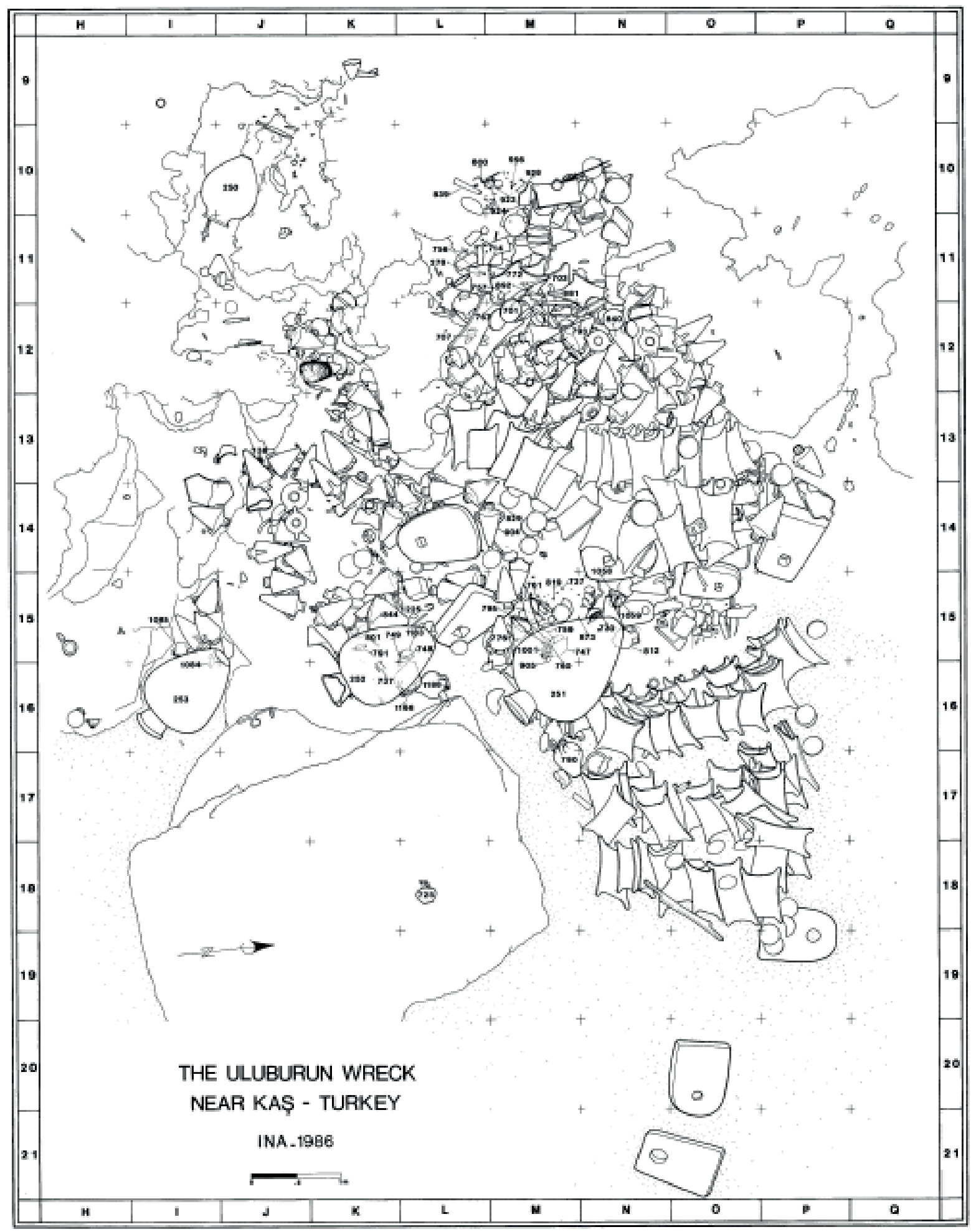

Figura 8. Planta de la situación en la que se encontraba el pecio de Ulu Burun tras la campaña de 1986 (Bass 1989: 3). 
láminas de cera es propio del Próximo Oriente (Gracia y Munilla 2004: 70-71). Los elementos identificables como chipriotas o micénicos, por citar dos procedencias de las argüidas en la literatura científica, no descartan la posibilidad de una tripulación mixta, pero entendemos que la iniciativa estatal, debido a la cualidad del cargamento, es ugarítica y bajo tal hay que entender la mayor parte de la tripulación y de los objetos hallados.

Otro dato que nos habla en favor de la estrecha relación entre los lingotes taurodérmicos y el mundo sirio es la serie de representaciones en tumbas egipcias desde el siglo XV hasta el XII a. C., apareciendo siempre portadores de clara vestimenta siria llevando sobre sus hombros lingotes taurodérmicos como tributo al difunto. El caso más citado en la bibliografía al uso sobre este tema es el de la tumba de Rekhmiré, precisamente por su carácter excepcional al aparecer representados en sus paredes portadores egeos, siendo ésta la única escena en la que personajes de tradición no cananea portan lingotes de este tipo de todos los ejemplos hallados hasta el presente en el mundo egipcio (fig. 9).

La estrecha conexión entre estos lingotes y el mundo sirio es tal que hasta la fecha el único molde para este tipo de lingotes ha sido hallado en Ugarit (actual Ras Shamra) (Lagarce y Lagarce 1997: 73-76). Pero a pesar de este paralelismo, es imposible negar la relación existente con la isla de Chipre. No obstante, quizás estemos
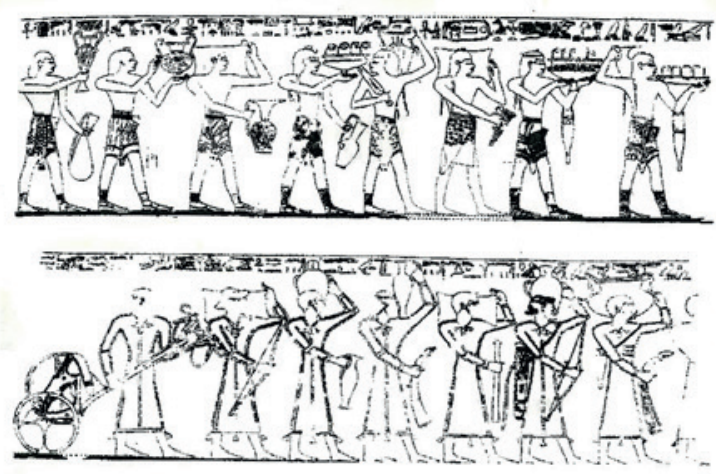

Figura 9. Portadores cretenses representados en la tumba de Rekhmire (arriba). Portadores sirios procedentes de la misma tumba (abajo) (Maier 2003: 93).

cayendo ante un doble espejismo: el de la procedencia chipriota de estos lingotes y el de tomar por tal todo objeto con cuatro prolongaciones en sus esquinas. Para el primer caso, un buen ejemplo lo tenemos en el molde recién citado encontrado en Ugarit (fig. 10). Sugerente para nuestra propuesta es que los análisis efectuados por N. Gale y por Z. Stos-Gale a los restos de cobre encontrados en forma de gotas alrededor del mismo han certificado la procedencia chipriota del metal, por lo que el origen de los metales que componían la aleación

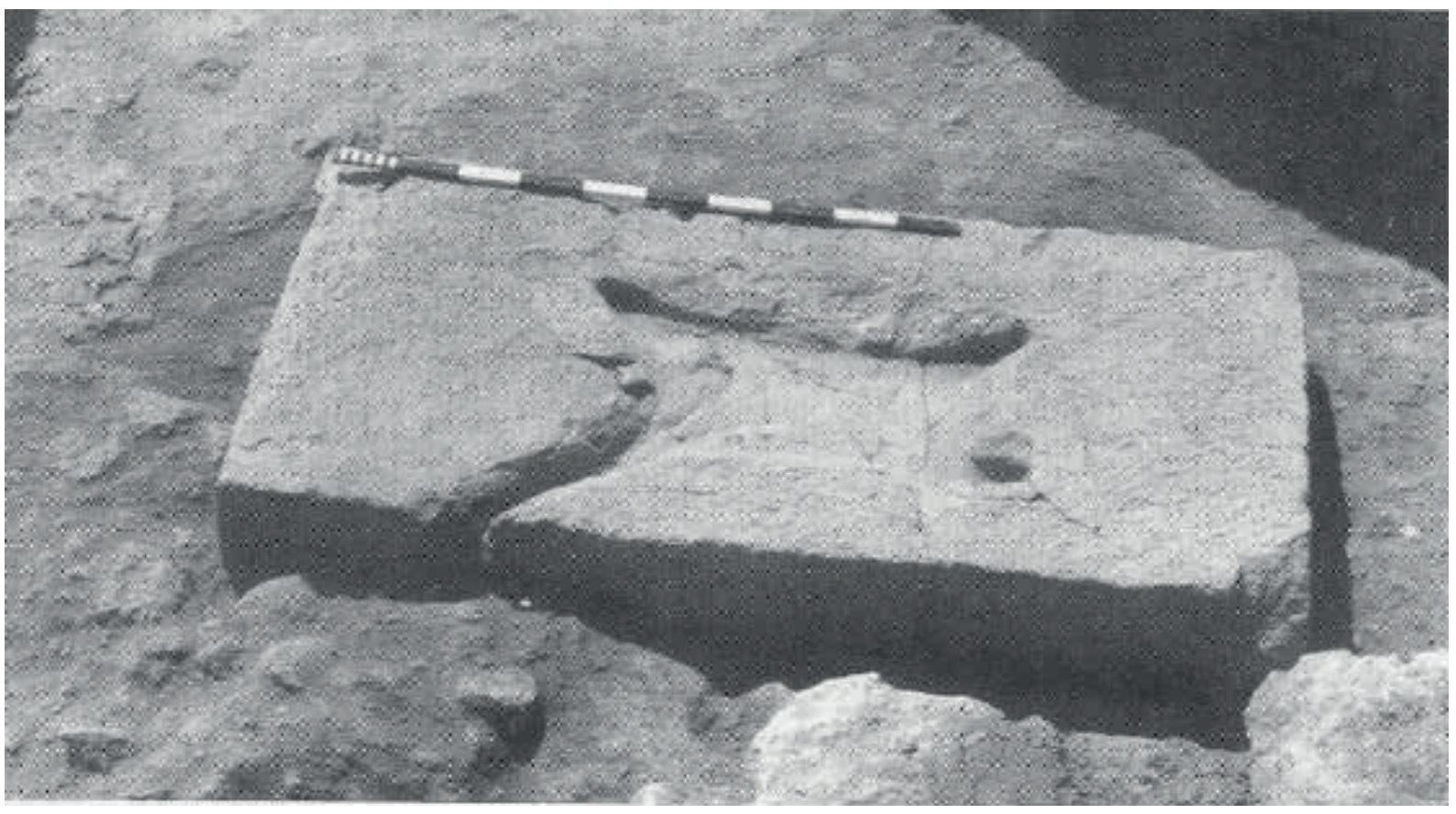

Figura 10. Molde ugarítico con forma de piel de toro (Lagarce y Lagarce 1997: 75).

ISSN: 1133-4525 ISSN-e: 2255-3924 
no indica que los lingotes hayan sido fabricados en Chipre (Lagarce y Lagarce 1997: 76). No obstante, J. Lagarce y E. Lagarce dejan ver la posibilidad de que el metal hubiera podido ser extraído del norte de Siria, en concreto del macizo de Bassit, una prolongación de la formación geológica chipriota. Sin embargo, hasta el momento tan sólo han aparecido en dicha zona cerámicas helenísticas, romanas y bizantinas que apuntan a la posibilidad de la explotación de esta zona durante esos períodos (Lagarce y Lagarce 1997: 76-77, nota a pie 9). Es más, como comenta J. Vidal, es probable que existieran en la propia Ugarit tanto fundidores como metalurgos, por lo que no había necesidad de traer el metal ya moldeado del exterior:

"Los trabajadores del metal aparecen referidos en la documentación ugarítica bajo el apelativo de $n s k$, literalmente 'fundidor'. Dicha categoría es posible que englobara las dos tareas principales relacionadas con la producción de objetos metálicos identificadas en el ámbito sirio gracias a las referencias recogidas en los archivos de Ebla y Mari: los fundidores (SIMUG / napp fum), encargados de la fundición y fusión de los metales, y los metalúrgicos (TIBIRA / qurqurrum), individuos dedicados al trabajo del metal con el fin de darle su forma definitiva" (Vidal 2003: 103).

Ante esta serie de datos, nos vemos en disposición de considerar la forma de estos lingotes como propios, no sólo del mundo chipriota, sino también del mundo ugarítico, y poder reinterpretar así desde la tradición siria una serie de formas aparecidas en cilindros-sellos hallados en Ras Shamra (Ugarit) y que han sido tradicionalmente interpretados como lingotes dado los paralelos con que se contaba hasta la aparición de los altares en la Península Ibérica. Se trata de dos sellos en los que aparecen sendas formas de piel de toro en un contexto claramente ritual.

En el primero de ellos, procedente del Museo de Aleppo (RS 6127), se observa a un hombre de pie afrontado a un animal estilizado al que se aproxima en actitud de cogerle por los cuernos, los cuales son de perfil curvado hacia atrás, lo que nos hace asimilar a este animal con una cabra. Tras ella, otro animal de menor estatura le sigue en la misma dirección. Ambos podrían estar siendo dirigidos hacia la pieza que se encuentra detrás de la figura humana ${ }^{2}$, de clara silueta taurodérmica y que aparece representada desde una visión cenital para que se vea su forma. Esta pieza podría

2. Los cilindros-sellos tienen la peculiaridad de no señalar cuál es el comienzo y el final de la escena. tratarse de un altar hacia el que ambas víctimas se estarían encaminando para ser sacrificadas (fig. 11). Entre el posible altar y el último de los animales, un pájaro de significado incierto, y entre ambos animales un símbolo astral representado por un conjunto de puntos identificable quizás con el cúmulo de las Pléyades, cierran el conjunto de figuras (Bordreuil y Gubel 1990: 484, fig. 2; Lagarce y Lagarce 1997: 80, fig. 4, imagen inferior).

De especial interés dentro del campo epigráfico resulta la inscripción aparecida en el sello: $s p$ (Bordreuil y Gubel 1990: 484). Estos dos signos, complicados de interpretar, deben de ser tomados en consideración según el lugar en el que se encuentran inscritos. Los cilindros-sellos identificaban, controlaban o sancionaban bienes relacionando con claridad su impronta gráfica con una autoridad o individuo. No obstante, en ocasiones se han encontrado ejemplares que por su contexto nos indican que se convirtieron también, por sí mismos, pero sobre todo por lo que representaban, en objeto preciado, en una joya que intervendría en los juegos de ostentación (Zamora 2006: 496). Los paralelos relacionables nos indican que aquellos cilindros-sellos con inscripción entendible llevan nombres de persona, con sus filiaciones y sus cargos en los casos más explícitos, desde el rey a los grandes magistrados ugaríticos. Los cilindros-sellos del área inmediata siria también tienen la misma pauta, pero en silabario mesopotámico. Siguiendo la opinión de J. A. Zamora (2006: 496 y ss.) $)^{3}$, podríamos considerar una introducción en Siria de la tradición mesopotámica de los cilindros-sellos desde muy antiguo por su funcionalidad, adaptándose pronto motivos gráficos locales e incorporando muy ocasionalmente textos, primero en toda el área en acadio y en el caso de Ugarit dado el éxito del alfabeto cuneiforme, también en el signario local. En estos casos, las inscripciones son siempre breves y difíciles, pero cuando se leen (con, además, una cierta longitud) son claros nombres de personajes, que se citan con su filiación y sus cargos. ¿Podríamos estar por tanto ante un antropónimo que nos indicase el nombre del personaje representado en la acción? ¿Podría interpretarse $s p$ como un nombre derivado de la advocación ugarítica spn?

En la segunda de las piezas (Lagarce y Lagarce 1997: 80, fig. 4 arriba) se observa la figura de un hombre sentado sobre una silla baja que porta unos cuernos en su cabeza similares también, como en el primer

3. Agradecemos a J. A. Zamora López su amabilidad para con nosotros a la hora de responder a nuestras dudas sobre la inscripción a estudio. 


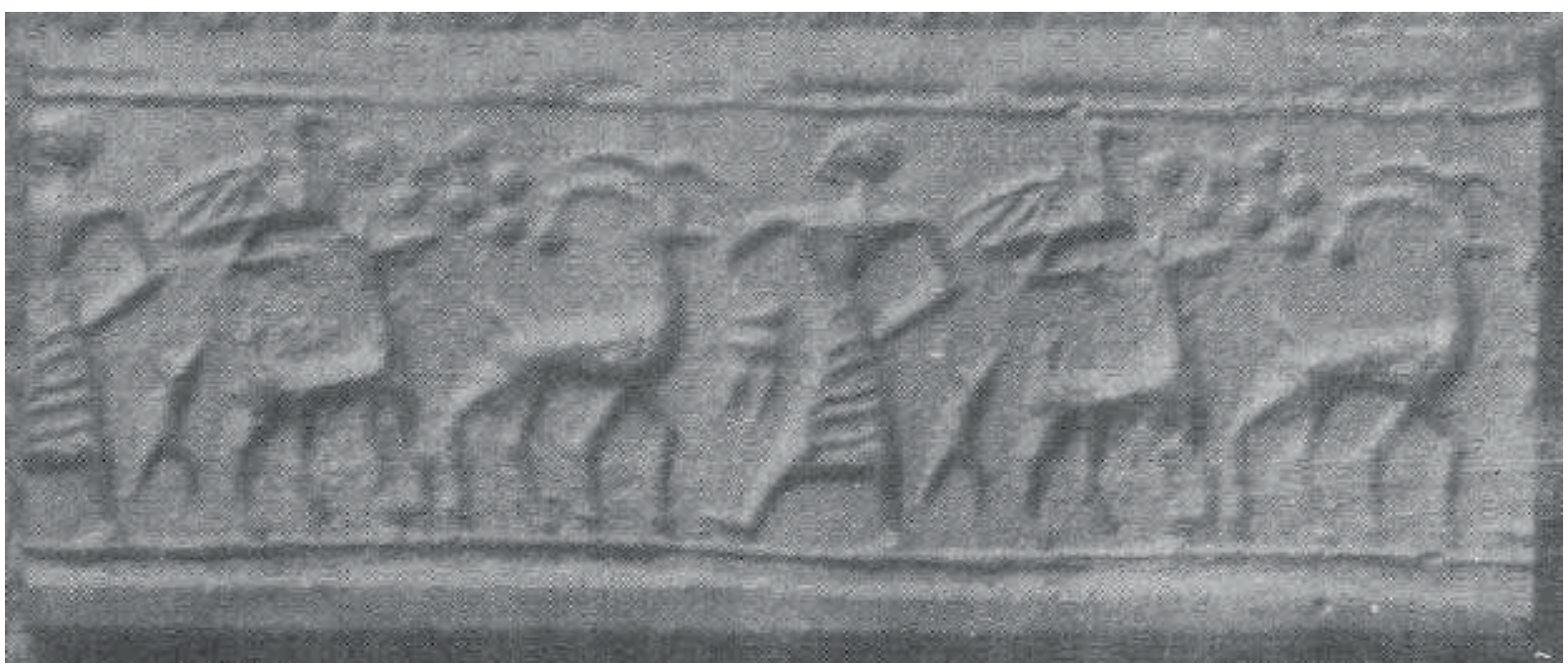

Figura 11. Cilindro-sello ugarítico actualmente en el Museo de Aleppo (Lagarce y Lagarce 1997: 80).

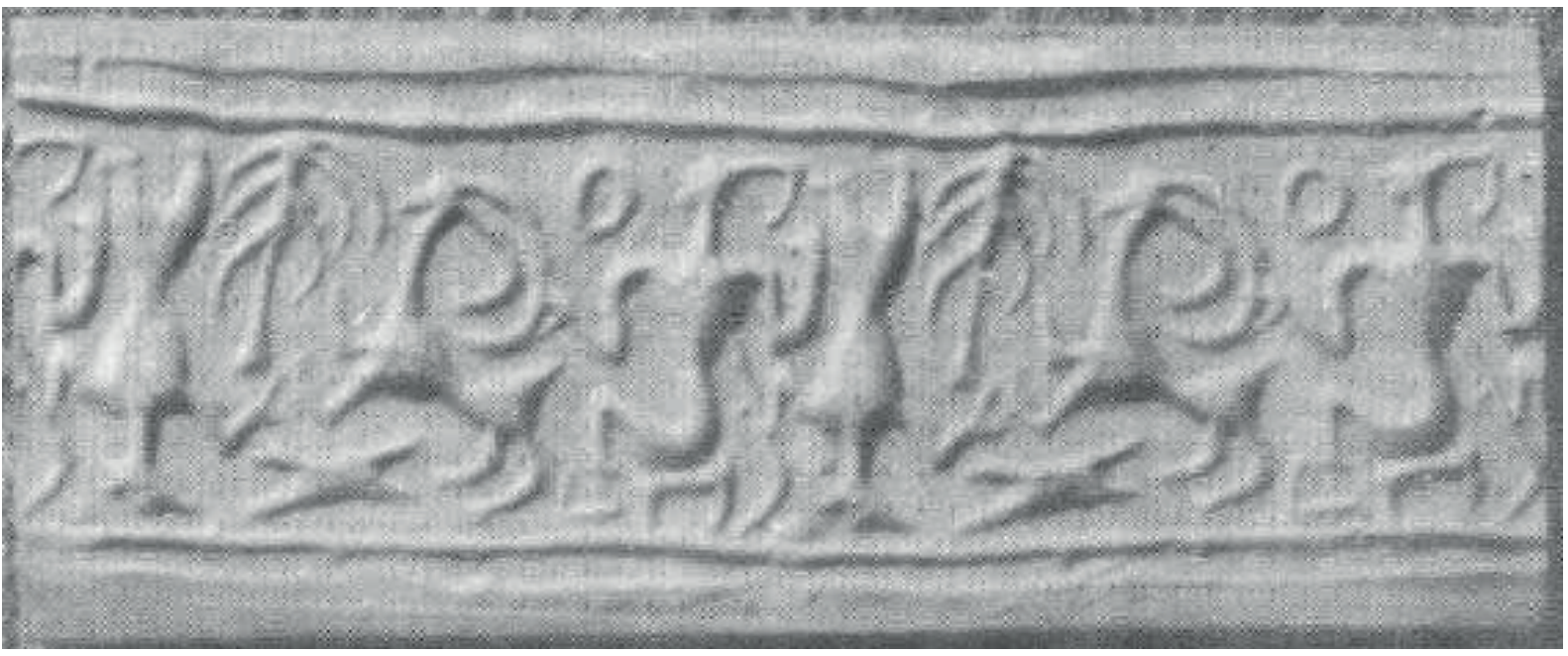

Figura 12. Cilindro-sello procedente de Ugarit (Lagarce y Lagarce 1997: 80).

sello, a los de una cabra, en ademán de coger a un animal de su cornamenta y alzando amenazante la otra mano quizás en actitud de sacrificio. Resulta sugerente a este respecto observar la posición en la que se encuentra el animal, de nuevo una cabra según la forma de sus cuernos, pues la mitad delantera de su cuerpo se encuentra sobre otro elemento de forma taurodérmica, esta vez representado desde su cenit en horizontal para que su forma pueda ser vista de acuerdo con la orientación del cuerpo del animal (fig. 12). Nuevamente interpretamos esta pieza como un altar taurodérmico, acompañado esta vez de un árbol identificable con una asherah, árbol sagrado de tradición cananea y fenicia que recoge las propiedades de las divinidades femeninas semitas (van der Toorn et al. 1999: 101). Un elemento más representado en el sello es una figura redondeada a la que se le representa su contorno y que relacionamos con un símbolo astral quizás identificable con el Sol o con la Luna. Todos estos elementos nos vuelven a hacer pensar que estamos ante la plasmación de un ritual sacrificial. Por último, una figura humana bocabajo sosteniendo un objeto alargado con su mano cierra la escena sin que podamos hipotetizar sobre ella.

De Chipre procede una buena muestra de cilindros-sellos en los que se aprecia la misma forma taurodérmica (fig. 13), de los que la mayor parte procede de Enkomi. Las escenas representan la misma temática que las procedentes de Ugarit pero no muestran 


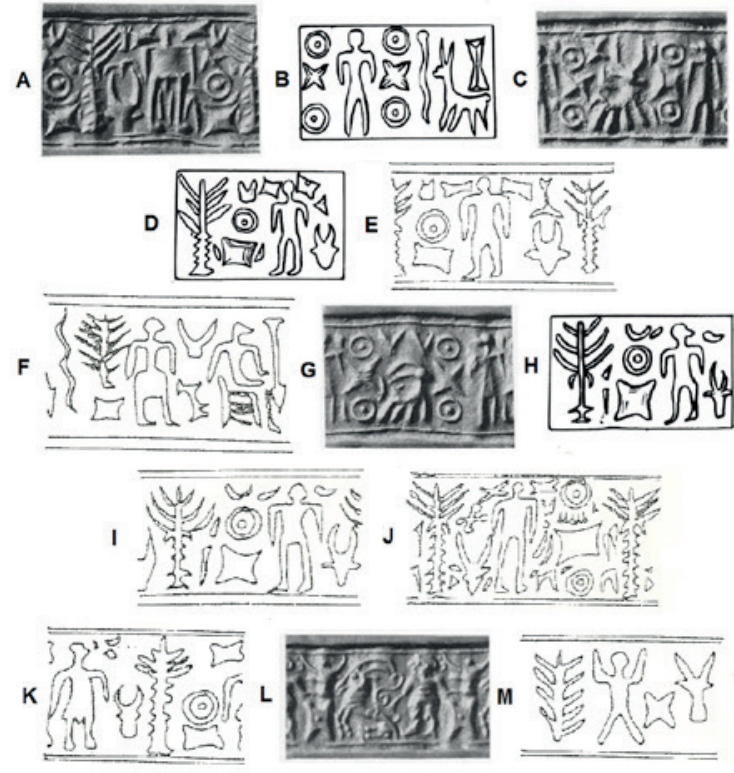

Figura 13. Improntas de cilindros-sellos procedentes de Chipre.

escenas con animales, sino otras más simbólicas en todos los casos que conocemos. En ellas se suelen repetir una serie de elementos ya vistos en los cilindros-sellos de Ugarit: un personaje masculino de pie, un supuesto lingote de forma taurodérmica, un árbol, una cabra y en ocasiones bucráneos o cornamentas. Los paralelos visibles con los ejemplares ugaríticos nos remiten al mismo ámbito religioso del que hemos hecho mención antes. Los hasta ahora considerados lingotes chipriotas (quizás deberíamos de decir siriochipriotas) son interpretados por nosotros como altares rodeados de todos los elementos relacionados con la práctica cultual recogidos en las piezas sirias. Así, junto a los altares vuelven a aparecer las asherah y los cráneos o cornamentas relacionables tanto con los hallados en los santuarios de Enkomi como en los cilindros-sellos hallados en la actual Ras Shamra. Un elemento sí que querríamos destacar de todos los aparecidos en los ejemplares que conocemos. Se trata de una figura formada por tres círculos concéntricos, interpretable como un signo astral al igual que el conjunto de puntos o el signo con doble contorno de los ejemplares ugaríticos. Pero queremos llevar más allá esta idea y especificar que podríamos estar ante una representación solar o lunisolar según los casos que se manifestaría en todas las ocasiones encima del altar, y cuando no lo hace no aparece en ninguna otra parte de los cilindros-sellos. Así, el ejemplar procedente de Kourion (fig. 13, A) tiene sobre el altar la imagen de un posible sol con un cuarto lunar, mientras que los demás muestran tan sólo a la figura solar sobre el altar. Quizás el más interesante para nuestros resultados sea el ejemplar hallado en Hala Sultan Tekke (fig. 13, J), sin duda el que más elementos presenta y el único en el que apreciamos una serie de triángulos entre el altar y el símbolo solar que interpretamos como las llamas que intentan reflejar el holocausto del sol, de ahí que podamos observar bajo el altar otro símbolo solar, probablemente de resurrección. En la misma línea se interpretaron las líneas grabadas en una de las caras de un vaso de mármol procedente de Sidón y datable en torno al s. IV a. C. como la representación del fuego que testimonia la muerte por combustión del dios sobre el altar, tratándose de un ejemplo más que ha sido relacionado con la muerte y resurrección de la divinidad baálica a través de una hipótesis astronómica y no relacionada con los ciclos de la naturaleza (Escacena 2009: 109). De igual modo, estas figuras de tipo astral aparecen sobre y bajo altares taurodérmicos en dos cilindros-sellos procedentes también de Chipre, destacando entre su glíptica un animal cornudo con un betilo sobre su lomo, representación de la divinidad anicónica de tradición semítica (fig. 13, B), lo que da un carácter más religioso si cabe a estas escenas, alejándolas de las interpretaciones metalúrgicas y pecuarias (Kenna 1967: 577).

Así, entre las características de este tipo de rituales, visibles en los cilindros-sellos de Ugarit, observamos algunas peculiaridades adscribibles al culto practicado en santuarios chipriotas como el de Enkomi, descrito más arriba. El primero tiene relación con los huesos hallados en la estancia principal del templo del "dios del lingote": se trata de una serie de cráneos de bóvidos que no conservan parte del esqueleto en la zona posterior y que dada esta característica ha servido a los investigadores para otorgarles un uso como máscaras rituales que serían usadas por los sacerdotes durante las liturgias. Este ejemplo nos remite a los cuernos que lleva sobre la cabeza la figura sedente del segundo de los cilindros-sellos aquí analizados procedente de Ugarit que tiene su mano en los cuernos de la cabra y levanta amenazante la otra. Quizás podamos afirmar con este paralelo que en este cilindro-sello estamos ante un sacerdote ataviado con una máscara de este tipo durante el ritual sacrificial. De igual modo, varias veces aparecen representados bucráneos y elementos que podrían ser relacionados con cornamentas, acaso relacionadas una vez más con los ejemplos citados procedentes tanto de los cilindros-sellos chipriotas como de los santuarios de la misma isla.

Junto a estas representaciones también se recogen, como en los ejemplares ugaríticos, asherah junto a los altares, lo que nos remite a un ambiente semítico 
claramente relacionado con el mundo cananeo. Cabe aquí recordar las referencias bíblicas que hacen alusión a la quema de las asherah y la destrucción de los altares de Baal (Deuteronomio 12, 3; Jueces 6, 25, entre otras). La dualidad altar-asherah dispone de multitud de referencias textuales en la Biblia a propósito de los "ignominiosos" altares baálicos (Jeremías 11, 13). Pero aparte de estas referencias escritas también tenemos ejemplos documentados tanto entre la toréutica oriental como entre los hallazgos de la Península Ibérica. Para el caso oriental, nos remitimos a tres piezas publicadas por separado pero recogidas en un mismo estudio a propósito de una de ellas por V. Karageorghis y G. Papasavvas (2001). Se trata de bases de trípodes de bronce en las que aparecen representados portadores de lingotes con faldellín y pecho descubierto presentándose ante un árbol que identificamos como una asherah (fig. 14). ¿Deben de interpretarse como lingotes? ¿Lingotes con un simbolismo religioso? ¿Lingotes votivos como los aparecidos en los santuarios del "dios del lingote" y del "dios con cuernos" de Enkomi entre otros lugares? ¿O quizás sean altares portátiles? Tanto si se tratase de lo primero como de lo segundo, ambas posibilidades podrían aunarse bajo un mismo denominador común, la de la piel de toro que simbolizaría la muerte de la divinidad y la resurrección de la misma, de ahí el carácter votivo de ciertos lingotes. Por tanto, estas representaciones en bases de quemaperfumes procedentes de Chipre y las relaciones que aquí anotamos entre los cráneos de Enkomi y los cilindros-sellos vienen a sumarse a las referencias realizadas anteriormente en nuestro estudio acerca de las imágenes aparecidas sobre estos elementos taurodérmicos, una de las cuales se halló en Enkomi, $\mathrm{y}$ de los lingotes hallados en el interior de santuarios del mismo yacimiento, creándose así una estrecha vinculación entre Ugarit y Chipre a través de esta forma. No sorprende por tanto que de tierras de Alasiya, y sobre todo de la que tradicionalmente ha sido considerada su capital, Enkomi, vengan la mayoría de las representaciones hasta la fecha encontradas, entre otros motivos por la mayor cantidad de excavaciones realizadas en la isla frente a la situación arqueológica en el actual Líbano.

Por último, unos elementos a tener en cuenta, casi siempre presentes sobre los hombros de los personajes aparecidos en los cilindros-sellos, son posibles lingotes de cobre que, en vez de aparecer portados de hombro a hombro, como en los mencionados soportes chipriotas, fueron representados a menor escala. Quizás no se trate de los famosos lingotes y sí de los lingotes votivos, de tamaño más reducido. Varios han sido localizados en Chipre con inscripciones y otro procede de

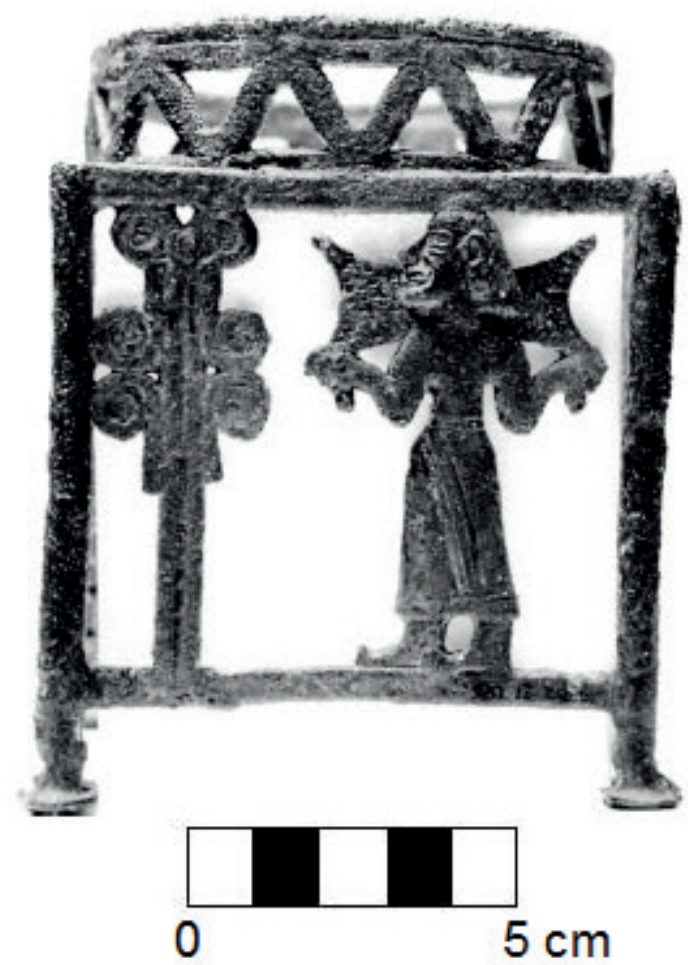

Figura 14. Base de un bronce procedente de Chipre en el que se observa a un portador de lingotes ante una asherah. ¿Se puede hipotetizar con un uso también religioso de los lingotes? (Karageorghis y Papasavvas 2001: 342).

Egipto (Marín 2006: 43). Otra hipótesis podría ser la que viera en estas piezas verdaderos lingotes que serían representados a tamaño más reducido por la necesidad de incluir dos en los sellos.

A la luz de estas representaciones podríamos reinterpretar los dos smiting gods comentados anteriormente. Hasta la fecha, tanto al "dios del lingote" como a su paredro de la colección Bomford se les ha identificado con sendas divinidades protectoras del trabajo de las minas y de la fertilidad de las mismas, lo que denota la clara identificación de las bases sobre las que se asientan las divinidades con los tan reiterativos lingotes de forma taurodérmica entre la bibliografía especializada. Sin embargo, a tenor de la hipótesis elaborada por J. L. Escacena (2007: 628, fig. 11), se puede interpretar que ambas figuras son la manifestación de la divinidad sobre el altar, lo que indefectiblemente obliga a relacionarlas con los símbolos astrales manifestados en los cilindros-sellos. No es algo de extrañar, pues es una constante que todas las divinidades sean relacionadas con elementos astrales, al igual que en el mundo antiguo se les ofrendaban animales como víctimas sacrificiales. 
De ahí que intentar relacionar a ambas divinidades con alguna advocación en concreto a partir de los signos aparecidos sobre ellos en los cilindros-sellos resulte a nuestro juicio bastante complicado. Sin embargo, son varias las aproximaciones que se han realizado a partir de las iconografías para intentar otorgar un nombre a las divinidades representadas en ambas estatuillas. Así, para el caso de la estatuilla del "dios del lingote", el primero en proponer una advocación para la misma fue su descubridor, C. F. A. Schaeffer (1971), quien postuló la identidad de Nergal-Reshef ya que, como divinidad supuestamente responsable de los trabajos mineros por estar sobre un lingote, relacionó a esta figura con el texto recogido en una carta procedente de los archivos de Tell El-Amarna del rey de Chipre a Amenofis IV poco tiempo después del advenimiento al trono del faraón, en torno a 1370 a. C. En dicha carta el rey de Chipre se excusa por no poder producir más cobre ya que la mano de Nergal, su señor, había matado a toda la población de su país. Nergal, de tradición babilónica, es considerado por C. F. A. Schaeffer como la misma advocación que el Reshef sirio a partir de una lista de dioses procedente de la biblioteca de un consejero del último rey de Ugarit, Hammurabi. De ahí que su descubridor le atribuyese esta identidad compartida. Nosotros distamos mucho de aceptar esta atribución para dicha estatua porque, como hemos señalado anteriormente, la base no representaría un lingote sino un altar, por lo que podríamos empezar a desmontar la hipótesis de que la representación de este dios tuviera relación con el cobre de la isla más allá de la mera relación formal entre los altares taurodérmicos y la forma de los lingotes que, recordemos, hasta ahora no hay por qué atribuir en exclusiva a Chipre, pues el único molde encontrado hasta la fecha procede de Ugarit y en él se han encontrado restos de cobre precisamente chipriota.

A este respecto creemos que la propuesta metodológica que utilizamos resulta válida, pues tanto la forma de los altares, las representaciones holocáusticas visibles junto a ellos, su carácter exento y su relación con símbolos astrales de carácter lunisolar encajan perfectamente en los cilindros-sellos analizados y, por extensión, con los smiting gods estudiados.

\section{ALTARES TAURODÉRMICOS ORIENTALES EN OCCIDENTE}

En un estudio anterior de carácter historiográfico abordamos la relación cronológica de los elementos con forma taurodérmica identificados hasta el momento en la Península Ibérica destacando que los tres altares inmuebles con forma de piel de toro trabajada más antiguos aparecidos hasta el presente en la Península Ibérica proceden de los yacimientos de El Carambolo (Camas, Sevilla), Caura (Coria del Río, Sevilla) y Malaka (Málaga), todos ellos aparecidos en santuarios de clara tradición oriental (Gómez Peña e. p.). La decisión por la cual sólo incluimos a estos tres ejemplares como los primeros viene justificada por ser los únicos que se han encontrado hasta la fecha datables entre el siglo IX y mediados del VI a. C., antes de que se perdiese el contacto con la metrópoli tiria. Curiosamente, es a partir de esta desvinculación y con el cambio de poderes en el comercio mediterráneo cuando este símbolo se expande por toda la Península Ibérica y desaparece en el área del suroeste, por lo que es conveniente tratar ambos períodos por separado.

\subsection{El Carambolo}

Los restos materiales aparecidos en las primeras excavaciones efectuadas en El Carambolo de la mano de J. M. Carriazo en 1958 dieron como resultado la identificación de los mismos con los restos propios de un poblado tartésico del Bronce Final para su fase inicial según se desprendía del análisis realizado por su excavador. No obstante, el propio J. M. Carriazo se mostró extrañado ante la riqueza del material cerámico aparecido y la modestia del fondo de cabaña en el que él consideró que se halló:

“[...] la calificación del fondo de cabaña no está exenta de alguna vacilación. Principalmente por su riqueza cerámica, desproporcionada a la pobreza de los demás materiales y del sistema constructivo, y no se diga a la del mismo tesoro, si, como creemos, está en relación con el yacimiento" (Carriazo 1970: 58).

Influenciado por J. M. Carriazo, A. Blanco consideró por su parte a El Carambolo como un lugar de culto tartésico al estilo de los de época geométrica y orientalizante del Egeo por lo rudimentario de las construcciones y lo singular de sus ajuares:

"A la vista de lo aparecido en éste [fondo de cabaña], cabría pensar en un lugar de culto como los del Egeo en épocas geométrica y orientalizante, antes de que se iniciase el desarrollo de lo que entendemos por templo griego. La totalidad de los edificios de culto (Kultbauten) reunidos por Drerup no tiene mayor prestancia ni dimensiones que las de este fondo de cabaña situado en el Carambolo. Eran 
entonces los templos edificios muy rudimentarios, de planta rectangular u ovalada, y sólo por la singularidad de sus ajuares se distinguían de las casas. [...] Desde esta perspectiva creo que no es ninguna extravagancia apuntar a la posibilidad de que el $<<$ fondo de cabaña $>$ del Carambolo haya sido un lugar de culto. Así encontraría explicación la abundancia de los ajuares, la presencia entre ellos de un tesoro, y por lo que a la cerámica se refiere, la aparición de esos vasos tan decorados y, por otra parte, de una pintura tan poco tenaz que no resistiría mucho a las manipulaciones del uso doméstico" (Blanco 1979: 95-96; la aclaración entre corchetes es nuestra).

Sin embargo, la interpretación que supuso un punto de inflexión fue la realizada por M. Belén y J. L. Escacena (1997). Ambos investigadores de la Universidad de Sevilla concluyeron tras revisar los materiales aparecidos y su contexto asociado que el yacimiento de El Carambolo no había sido un poblado tartésico, sino un santuario dedicado a Astarté, donde las principales edificaciones, enclavadas en el denominado Carambolo Bajo, contarían con todas las dependencias propias de estos enclaves sacros de carácter empórico por su ubicación costera y su dependencia de la fundación de Ispal. Como expresa J. L. Escacena (2010: 100) "no se trataría tanto de un poblado con su templo como de un templo con su poblado, matiz especialmente interesante a la hora de explicar el registro arqueológico del lugar y el de sus alrededores".

Fue posteriormente cuando recientes excavaciones arqueológicas dieron la razón a ambos investigadores. Debido a la intención de construir un hotel en el solar antes ocupado por las instalaciones de Tiro de Pichón, se realizó una serie de intervenciones desde 2001 a 2005 en las que se excavó la casi totalidad del cerro, saliendo a la luz un complejo sacro con cinco fases constructivas que desveló la existencia de dos altares en diferentes momentos constructivos junto a otros elementos de clara tradición oriental. Se trata de los altares más antiguos encontrados hasta el presente en la Península Ibérica, cada uno de los cuales pertenece a las fases IV y III respectivamente. Su contorno evidencia un tipo de forma aparecido repetidamente en los lingotes orientales caracterizado por el marcado alargamiento de las extremidades y es el mismo tipo documentado también en la base de los smiting gods como manifestaciones divinas sobre el altar (Escacena 2007: 628, fig. 11).

¿Podríamos considerar a estos altares de El Carambolo como creaciones propias del mundo tartésico? Como acabamos de ver, su forma no es nueva en el Mediterráneo, y sí que resulta novedosa para la tradición religiosa de la población residente, al igual que también resultan novedosos los modos de construcción empleados, tanto por el uso de adobes como por la realización de edificios de planta rectangular que acerca al complejo arquitectónico nuevamente a la tradición oriental (Fernández y Rodríguez 2007). Tal es el drástico cambio que este hecho implica que ha servido a algunos investigadores para basarse en él a la hora de utilizarlo como un demarcador cultural frente a la tradición constructiva de planta rectangular de la población residente (Izquierdo 1998).

Pero más allá de la tradición constructiva los rasgos orientales no se limitan a esta característica. Así, numerosos objetos de claro carácter religioso nos evidencian que la tradición cultual de quienes encabezaron el uso del edificio era también oriental. Ya en la reinterpretación que del lugar hicieron M. Belén y J. L. Escacena se llamó la atención sobre la singularidad de muchas de las piezas exhumadas por J. M. Carriazo para haber sido relacionadas con un ámbito doméstico (Belén y Escacena 1997). Así, la considerada trompeta de Argantonio había sido ya reinterpretada por uno de ellos como el pie de un posible thymiaterion claramente oriental (Izquierdo y Escacena 1998), la interpretada como repisa enlosada de sillares fue reinterpretada como banco corrido de tradición marcadamente oriental, las "piedras raras" en expresión de J. M. Carriazo fueron consideradas por ellos como posibles betilos anicónicos de sobra conocidos en el mundo semita.

Tras las intervenciones realizadas por A. Fernández y A. Rodríguez en el mismo cerro han podido ser documentados nuevos datos que siguen hablando en favor de esta hipótesis. De todos ellos queremos centrarnos por la temática de este estudio en el altar, nuevo elemento a sumar a la lista de objetos de raigambre oriental visibles en este santuario empórico. El complejo cultual de El Carambolo ha conservado los restos de un ara con dos etapas constructivas pertenecientes a las fases IV y III según la terminología asignada por sus excavadores. El perteneciente a la fase IV, hallado en la estancia A-40, fue fabricado mediante un suave rebaje del pavimento de tierra apisonada, pintada de rojo posteriormente y con unas dimensiones de 3,05 $\mathrm{m}$ de largo por 1,42 $\mathrm{m}$ de ancho. Sus excavadores apreciaron cuatro reformas del mismo y un gran círculo rubefactado debido a la combustión de las ofrendas sobre el altar (Fernández y Rodríguez 2007: 120). Su forma imita a una piel de toro tanto en sus características formales estilizadas como en sus características cromáticas con la zona exterior más clara que la interior debido a la menor y mayor concentración respectivamente de 
pelo que ofrecen las pieles de estos animales a la hora de ser despellejados. Un dato polémico para cerrar este apartado descriptivo es el concerniente a las cronologías otorgadas a esta fase del edificio, pues mientras que la cronología relativa fecha este nivel habitacional entre finales del siglo VIII y principios del VII a. C., la cronología absoluta lo hace entre el 830/810 a. C. (fecha ante quem de la fase V) y el 791 a. C. (fecha post quem de la fase III) (Fernández y Rodríguez 2007: 125); por su parte, el altar de la fase III, también encontrado en la estancia A-40 y superpuesto a aquel, fue nuevamente construido en el pavimento. Sus excavadores comentan que fue realizado mediante la disposición de una capa arcillosa sobre el altar previo, de entre 2 y $4 \mathrm{~cm}$, en la cual se modeló en negativo la forma de la piel de toro extendida, con un tamaño superior (4 $\mathrm{m}$ de longitud por 1,90 $\mathrm{m}$ de anchura). También se observaron huellas de combustión sobre él (Fernández y Rodríguez 2007: 136-137). Para esta fase, los autores le asignan una cronología relativa aproximada en torno a la primera mitad del siglo VII a. C., mientras que mediante datación absoluta el arco cronológico calibrado es de 791-506 a. C.

Queda patente el origen oriental de este edificio, cuestión no baladí si tenemos en cuenta que es el santuario empórico más antiguo aparecido en la Península Ibérica, al igual que los altares taurodérmicos. La vinculación por tanto del complejo arquitectónico con la tradición cultual oriental y con una divinidad ligada al mar es en nuestra opinión innegable.

\subsection{Caura}

El segundo altar aquí mencionado es el del yacimiento de Caura. Muy cerca geográficamente de El Carambolo, su ubicación sobre un promontorio justo en la antigua desembocadura del Guadalquivir (Roos et al. 1995) le confirió un enclave estratégico para el comercio colonial. Ya antes de efectuarse excavaciones en él, M. Belén planteó la hipótesis de que en el lugar podría haberse ubicado un santuario empórico identificable con el Mons Cassius de la Ora Marítima de Avieno por un ancla de piedra hallada en superficie antes de las intervenciones que presentaba una tipología muy similar a otras anclas halladas en el Mediterráneo Oriental y depositadas en santuarios empóricos como ofrenda votiva en señal de agradecimiento a la divinidad por permitir llegar a los marineros sanos y salvos a puerto (Belén 1993). Dicha hipótesis se reforzó poco tiempo después al excavarse el cerro de San Juan y sacarse a la luz parte de un santuario con cinco fases constructivas sucesivas en el que aparecieron dos altares taurodérmicos superpuestos, al igual que ocurre con el caso de El Carambolo. También como en este yacimiento, las aras ofrecen un contorno similar a la forma de piel de toro dada a algunos de los lingotes orientales, con lo que se refuerza la relación de procedencia de ambas ideas: lingotes y altares vinculables con el mundo siriochipriota.

La extensión de las excavaciones fue menor que en la posterior intervención de El Carambolo y en proporción a ello el número de hallazgos también, pero cabe ser citada aquí una serie de características sobre el origen oriental de estas edificaciones realizadas por sus excavadores que refuerzan nuestra hipótesis. En primer lugar observamos nuevamente una arquitectura de muros rectos cuya tradición en el suroeste de la Península Ibérica se hallaba ausente durante los últimos siglos del II milenio a. C. A ello se suman las medidas de las paredes excavadas y de sus cimientos infrapuestos, los cuales suelen tener en torno a $55 \mathrm{~cm}$. de grosor, tamaño correspondiente al codo grande púnico (Escacena e Izquierdo 2001: 147).

También se encontraron bancos corridos adosados a la capilla como en el caso de El Carambolo quizás como asientos para la celebración de symposia o bien como mesas para colocar materiales relacionados con el culto y sus prácticas. De igual modo algunos fragmentos de huevos de avestruz o escarabeos (Conde et al. 2005) nos hablan en favor de la singularidad religiosa de este recinto.

Por último, otro dato a valorar procede del Santuario III, muy cerca del altar de forma taurodérmica. Se trata de un círculo negro de unos $20 \mathrm{~cm}$ de diámetro que apareció junto al extremo superior derecho del ara conteniendo carboncillos, huella al parecer de un elemento cilíndrico de madera hincado en posición vertical. Cuando J. L. Escacena y R. Izquierdo publicaron estos datos hipotetizaron con la posibilidad de estar ante una posible asherah (Escacena e Izquierdo 2001: 134). También en El Carambolo apareció próximo al altar de la fase III una pequeña estructura de planta circular localizada al extremo noreste de aquél que estaba formada por un pequeño adobe rehundido con una capa de mortero a base de tierra margosa (Fernández y Rodríguez 2007: 120) (fig. 15) que bien pudo haber servido para colocar en ella otra asherah. De ser cierta esta interpretación tendríamos un paralelo más para relacionar los contextos religiosos en los que han aparecido estos altares con las representaciones de los cilindros-sellos en los que, como vimos anteriormente, se representaron posibles asherah siempre al lado de las aras. Nuevamente, a 


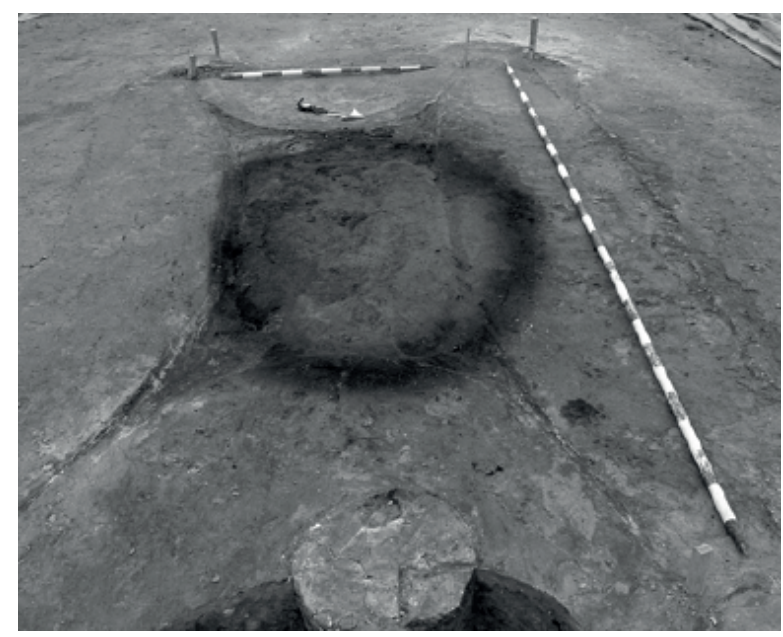

Figura 15. Altar de El Carambolo con la huella de la asherah en la parte inferior de la imagen (Escacena 2007: 646).

la luz de todos estos hallazgos consideramos que el carácter oriental de estos altares es difícilmente discutible en el estado actual de las investigaciones.

\subsection{Malaka}

Los últimos ejemplos de altares encontrados en la Península Ibérica datables entre el siglo IX y mediados del VI a. C. proceden del yacimiento fenicio de Malaka, en concreto del sector de c/ Císter-San Agustín. De nuevo, al igual que para el caso de los altares de El Carambolo y de Caura, éstos han sido hallados en un santuario de clara tradición fenicia enclavado en un poblado de igual adscripción cultural, lo que refuerza si cabe la hipótesis de que los dos santuarios anteriores sean de tradición oriental. Dicho complejo cultual ha sido fechado entre el siglo VII y mediados del VI a. C. (Arancibia y Escalante 2006: 338), situándose en un lugar elevado y estratégico alzado por encima de la bahía y controlando a la misma.

La construcción del altar A tuvo dos fases, dibujándose todo el contorno exterior incluidos sus apéndices, cuya diferencia de coloración con la parte interna nos desvela nuevamente la intención de imitar una piel de toro trabajada, teniendo su paralelo más cercano en los de Caura. Misma factura y mismo tratamiento tuvo el ara B.

De momento no podemos precisar más sobre este asentamiento, pues el estudio de los materiales todavía no ha sido publicado, por lo que nuevamente hay que considerar con cautela las conclusiones a las que se lleguen a falta de poder conocer nuevos datos.

\section{CONCLUSIONES}

Durante todo el presente estudio hemos intentado demostrar el origen oriental de la idea del uso de la piel de toro trabajada como símbolo de resurrección divina y más concretamente de los altares de forma taurodérmica. Con esta hipótesis de trabajo no es necesario hacer derivar a éstos de los lingotes antes analizados, como hasta ahora se ha venido haciendo por un gran número de investigadores. Ambos elementos, lingotes y altares, responden a una idea común: la piel de toro trabajada. Con lo que no estamos de acuerdo es en adjetivar como chipriotas a este tipo de lingotes (y por tanto a su forma), cuyo único molde hallado hasta ahora procede de Ugarit, habiendo sido transportados por el Mediterráneo en pecios como los de Ulu Burun y Cabo Gelidonya de tradición siria, con tripulación en su mayoría siria e incluso los portadores de los lingotes aparecen en las tumbas egipcias vestidos con ropas típicamente sirias. A ello hay que sumar una representación procedente de Karnak en la que el faraón Amenofis II asaetea un lingote (fig. 16) en una clara muestra simbólica de fuerza y de relaciones internacionales, pues como advirtió J. Maier, fue su padre Tutmosis III quien había derrotado pocos años antes a una coalición siriopalestina en Megiddo (Maier 2003: 96). Es por lo que proponemos la denominación siriochipriota como término más globalizador para los lingotes de forma taurodérmica, lo que encajaría con el origen de los altares del mismo tipo.

Para nosotros, por tanto, no queda duda del origen oriental de los altares taurodérmicos y de su vinculación siriochipriota, visible no sólo en su forma, sino en las tradiciones cultual y cultural. No obstante, somos conscientes de que los ejemplos más estrechos, los siriochipriotas, tienen un vacío en el registro arqueológico bien

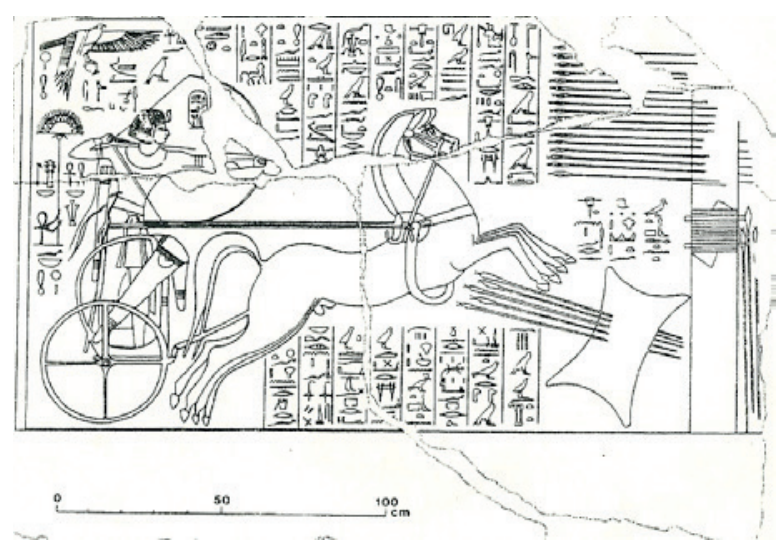

Figura 16. Escena de propaganda en la que Amenofis II asaetea un lingote (Maier 2003: 96). 
claro entre 1200-900 a. C. Trescientos años que separan a los ejemplares orientales de los occidentales y que, como bien apuntó S. Celestino (1994) es una cuestión a resolver, aunque autores como P. James tendrían clara la solución (James 1993). Independientemente de esta problemática, la continuidad en la factura y en los rituales asociados a los taurodermos es constante.

Mención aparte merecen las explicaciones dadas para la simbología que reflejan estos altares por parte de los diversos autores:

El primero en realizar una hipótesis sobre el significado de esta forma fue M. Almagro-Gorbea. La aparición de los taurodermos aparecidos tanto en la base del monumento funerario de Pozo Moro como en las tumbas ibéricas que se publicaron en el Congreso de Arqueología Ibérica en 1992 le llevaron a hipotetizar la posibilidad de que se tratase de un símbolo relacionado con el culto dinástico vinculado a la transmisión de poder (Almagro-Gorbea 1993-1994: 124).

Para S. Celestino, siguiendo la propuesta de M. Bendala, a pesar de que la mayoría de los ejemplares de forma taurodérmica documentados hasta aquel momento tenían una clara relación funeraria, era más oportuno interpretar esta forma en general, y los altares de Cancho Roano en particular, como una expresión de religiosidad de carácter divino más que con una expresión del status de poder (Celestino 1994: 307).

Una tercera hipótesis que aunó ambas interpretaciones fue la propuesta por J. Maier, quien relacionó esta forma con un símbolo propio del dios Baal Hadad, advocación para él de carácter atmosférico personificado por un toro, de ahí el uso de la piel de este animal en los altares. También J. Maier Allende relacionó a esta advocación baálica con la protección de las minas y de la metalurgia dada la forma de los lingotes y la relación de los santuarios chipriotas con el trabajo del metal (Maier 2003: 97-99), siguiendo así la interpretación tradicional. Por extensión de esta última asimilación, relaciona dicha simbología con los monarcas sacros orientales, entroncando así la hipótesis divina de S. Celestino con la de M. Almagro-Gorbea.

Para nosotros, la relación de los altares taurodérmicos con el significado divino de la piel de toro es innegable. No podemos afirmar sin embargo tan a la ligera la relación exclusiva entre este símbolo y las élites políticas, ya que conocer la idiosincracia religiosa de las capas más modestas de la sociedad suele tener como problema la parquedad de los datos recogidos en las intervenciones sobre este particular, más si cabe cuando las auténticas pieles, y no sus plasmaciones en barro cocido o en objetos metálicos, son tan perecederas como otros muchos elementos de difícil identificación dadas las condiciones de la Península Ibérica para su conservación.

Por su parte M. C. Marín realizó un análisis exhaustivo de la evocación que sugería la piel de toro como elemento para realizar pactos y tratados ya que se trata de la ofrenda más prestigiosa debido a su precio de mercado en diferentes momentos de la Historia en el área mediterránea (Marín 2006). Existen varias fuentes textuales que hacen referencia al uso de la piel de bóvido como medio para realizar pactos, sin embargo las generalizaciones que hace la autora para entender este símbolo como un elemento que no es reducible a una advocación en concreto no son desde nuestra perspectiva correctas. Así en algunos de los ejemplos utilizados para tal fin por esta autora las fechas en las que nos movemos son muy posteriores a las usadas por nosotros en nuestro estudio: el texto de Luciano (siglo II d. C.) sobre una costumbre escita, la tradición de realizar acuerdos de carácter público sobre una piel de buey en época romana y el casamiento en época musulmana sobre la misma. No así para el ejemplo de la fundación de Cartago vinculada al uso de la piel de bóvido, que obvia decir que es precisamente una colonia de tradición fenicia, en la que además las referencias a los bóvidos en este caso no son vinculantes con un pacto. ¿Podemos así pensar que la costumbre de usar pieles de toro tanto en época romana como en momentos posteriores sea una pervivencia de la tradición fenopúnica? Quizás en este caso el bosque no nos deje ver los árboles y la aparente generalidad de este símbolo deba de ser analizada diacrónicamente y no sincrónicamente.

Por su parte, J. L. Escacena (2007) sostiene que la forma de estos altares estaría vinculada con la identificación táurica de la divinidad a la que estuvieron dedicados y con su cíclica muerte y resurrección, a veces transfigurado en bóvido, a veces en sol, según se desprende de la mitología oriental y de las representaciones que han llegado hasta nuestros días, de ahí la orientación hacia los solsticios de verano y de invierno de estas piezas. Si bien esta interpretación nos parece acertada, consideramos necesaria complementarla con la hipótesis propuesta por F. López Pardo (2006), quien independientemente de si se trata de un símbolo elitista o no, ve en la piel de toro un símbolo de resurrección que separa dos planos. Debido a esto hipotetiza con la posibilidad de que esta relación vinculase a la divinidad baálica con el plano subterráneo y con el trabajo metalúrgico visible tanto en los templos orientales (casos de Ugarit o de Enkomi) como en los de la Península 
Figura 17. Monumento tallado en una tumba de

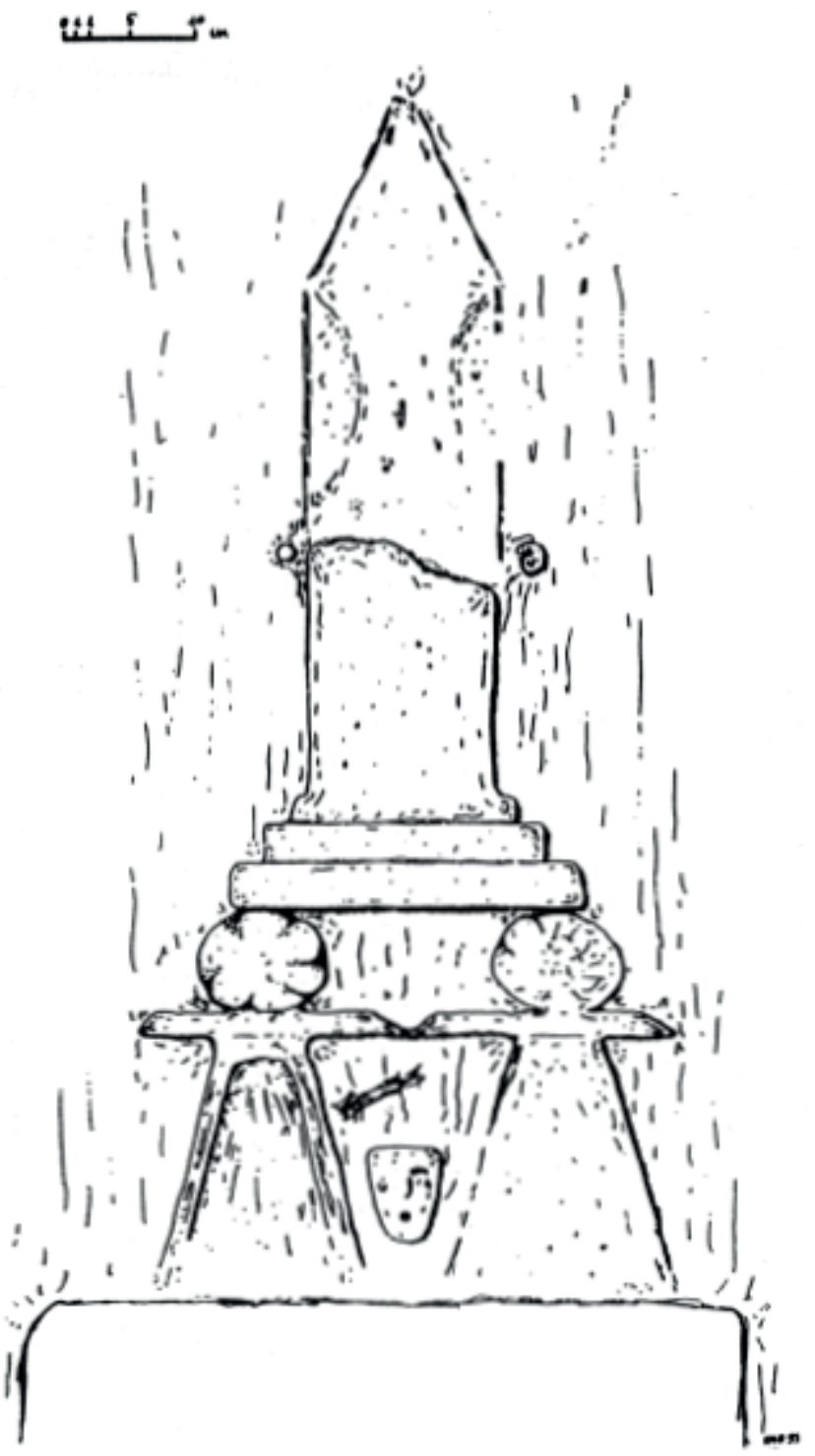

Ksar es Sâad (Túnez) (López Pardo 2006: 58).

Ibérica (La Muela o Malaka), por ser de la tierra de donde se extrae el metal. Así, nuevamente, la idea de la piel de toro como símbolo divino habría derivado en la creación de altares de forma taurodérmica y en la elaboración de lingotes con el mismo perfil bajo la esfera de influencia sacerdotal.

La idea elaborada por F. López Pardo es aplicable a la representación de la piel de toro tanto en los altares, como lugar donde resucita la divinidad (hasta aquí nada nuevo), como en contextos funerarios, donde el difunto realizaría un tránsito desde el inframundo a otro plano pasando por la piel de toro visible en varias bases y cubiertas de tumbas de época ibérica. La tradición fenicia de esta idea de nuevo es clara si tenemos en cuenta la representación de una piel de toro sobre una estela igualmente tallada en una tumba de Ksar es Sâad (Túnez) (fig. 17):

"[...] la huella de la "piel de toro", que conecta con el mundo subterráneo, seguramente con connotaciones positivas de resurrección baálica (?) es la que separa el plano inferior con el que se encuentra sobre la tierra, el etéreo, también el que delimita el espacio sagrado que no deberá traspasarse sin purificación previa" (López 2006: 58). 


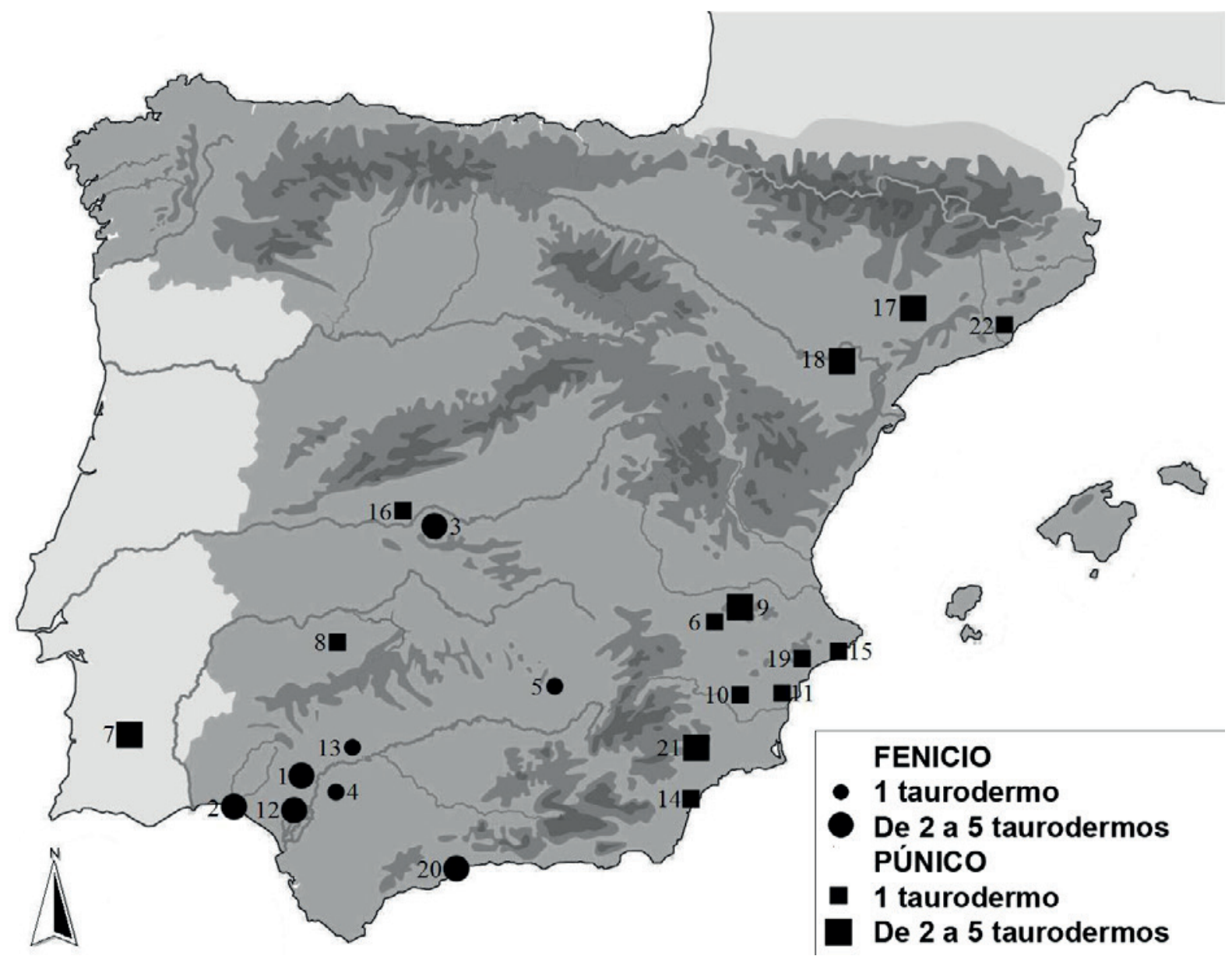

Figura 18. Distribución de los taurodermos protohistóricos con significado religioso hallados en la Península Ibérica: 1. El Carambolo (Camas, Sevilla), 2. Huelva, 3. Belvís de la Jara (Toledo), 4. Alcalá de Guadaira (Sevilla), 5. Cástulo (Linares, Jaén), 6. Pozo Moro (Chinchilla de Monte-Aragón, Albacete), 7. Neves (Castro Verde, Alentejo), 8. Cancho Roano (Zalamea de la Serena, Badajoz), 9. Los Villares (Hoya Gonzalo, Albacete), 10. Castillejo de los Baños (Fortuna, Murcia), 11. El Oral (San Fulgencio, Alicante), 12. Coria del Río (Sevilla), 13. Lora del Río (Sevilla), 14. Villaricos (Almería), 15. Villajoyosa (Alicante), 16. Alcolea de Tajo (Toledo), 17. Els Vilars (Arbeca, Lérida), 18. La Tallada (Caspe, Zaragoza), 19. Monforte del Cid (Alicante), 20. Málaga, 21. Lorca (Murcia) y 22. Ca N’Olivé (Cerdanyola del Vallès, Barcelona).

Todas estas conclusiones refuerzan si cabe nuestra idea de que los altares taurodérmicos encuentran su origen en el Mediterráneo Oriental y acercan más si cabe las características de los hallazgos realizados en los santuarios datables entre el siglo IX a. C. y mediados del siglo VI a. C. de la Península Ibérica en que han aparecido este tipo de altares y la tradición religiosa cananea y fenicia.

Pero no sólo son adscribibles los altares taurodérmicos, muebles e inmuebles, encontrados durante el Hierro I a esta tradición oriental. En un estudio previo (Gómez Peña e. p.) dejábamos constancia de la gran concentración de ejemplares en el suroeste de la
Península Ibérica precisamente entre el siglo IX y mediados del VI a. C. (fig. 18). Saber hasta qué punto unas tradiciones plasmadas en realidades físicas (cerámicas, altares taurodérmicos, modelos arquitectónicos) llegan a traspasar las fronteras de un grupo social para ser utilizadas e interiorizadas por otros es, y probablemente seguirá siendo, uno de los eternos problemas de la arqueología de las identidades. Sin embargo, desde nuestra óptica, resulta más sencillo científicamente poder explicar cómo desde unos parámetros continuistas propiamente orientales aparecen estos elementos por las costas de la Península Ibérica, que explicar cómo y por qué la población residente asumió dichos elementos, 
toda vez que en el suroeste de la Península Ibérica desaparecieron en el tránsito del Hierro I al Hierro II. Por tanto, desde nuestra perspectiva, resulta más razonable asumir como propiamente orientales estas manifestaciones religiosas, sumándose así los altares a una larga lista de objetos de carácter cultual que cruzaron en la mentalidad de los viajeros el Mediterráneo de extremo a extremo.

\section{BIBLIOGRAFÍA}

ALMAGRO-GORBEA, M. (1993-1994): "Ritos y cultos funerarios en el mundo ibérico", Anales de Prehistoria y Arqueología 9-10: 107-134.

ARANCIBIA, A. y ESCALANTE, M. M. (2006): “La Málaga fenicio-púnica a la luz de los últimos hallazgos", Mainake XXVIII: 333-360.

BALMUTH, M. S. y TYLECOTE, R. F. (1976): “Ancient Copper and Bronze in Sardinia: Excavation and Analysis", Journal of Field Archaeology 3, 2: 195-201.

BASS, G. F. (1961): "The Cape Gelidonya Wreck: Preliminary Report", American Journal of Archaeology 65, 3: 267-276.

- (1986): “A Bronze Age Shipwreck at Ulu Burun (Kas): 1984 Campaign”, American Journal of Archaeology 90, 3: 269-296.

- (1989): "The Bronze Age Shipwreck at Ulu Burun: 1986 Campaign", American Journal of Archaeology 93, 1: 1-29.

- (1991): "Evidence of trade from Bronze Age shipwrecks", en N. H. Gale (ed.), Bronze Age trade in the Mediterranean (Studies in Mediterranean Archaeology Vol. XC), Jonsered: 69-82.

BELÉN, M. (1993): "Mil años de historia de Coria: la ciudad prerromana", Azotea 11-12: 35-64.

BELÉN, M. y ESCACENA, J. L. (1997): “Testimonios religiosos de la presencia fenicia en Andalucía occidental", Spal 6: 103-131. http://dx.doi.org/10.12795/ spal.1997.i6.07

BIKAI, P. M. (1987): The Phoenician pottery of Cyprus. Nicosia, Leventis Foundation.

BLANCO, A. (1979): Historia de Sevilla. La Ciudad Antigua (De la Prehistoria a los Visigodos). Sevilla, Servicio de Publicaciones de la Universidad de Sevilla.

BORDREUIL, P. y GUBEL, E. (1990): "Bulletin d'antiquités archéologiques du Levant inédites ou méconnues VI", Syria 67: 483-520.

BUCHHOLZ, H.-G. (1988): “Der Metallhandel des Zweiten Jahrtausends in Mittelmeerraum", en M. Heltzer y E. Lipinski (eds.), Society and Economy in the Eastern Mediterranean (c. 1500-1000 B.C.) (Orientalia Lovaniensia Analecta 23): 187-228. Eutigeverij Peeters, Leuven.

BUCHHOLZ, H.-G. y KARAGEORGHIS, V. (1973): Prehistoric Greece and Cyprus: an archaeological handbook. Phaidon, London.

CARRIAZO, J. M. (1970): El tesoro y las primeras excavaciones en "El Carambolo" (Camas, Sevilla) (Excavaciones Arqueológicas en España 68). Ministerio de Educación y Ciencia, Madrid.

CATLING, H. W. (1971): “A Cypriot bronze statuette in the Bomford collection", en C. F. A. Schaeffer (dir.), Alasia I, Tome IV: 15-32. Paris.

CELESTINO, S. (1994): "Los altares en forma de "lingote chipriota" de los santuarios de Cancho Roano", Revista de Estudios Ibéricos 1. La escultura ibérica: 291-310.

CELESTINO, S. y JULIÁN, J. M. (1991): “El caballo de bronce de Cancho Roano", Cuadernos de Prehistoria y Arqueología de la Universidad Autónoma de Madrid 18: 179-188.

CONDE, M.; IZQUIERDO, R. y ESCACENA, J. L. (2005): "Dos escarabeos del santuario fenicio de Caura en su contexto histórico y arqueológico”, Spal 14: 7589. http://dx.doi.org/10.12795/spal.2005.i14.03

ESCACENA, J. L. (2007): "El dios que resucita: claves de un mito en su primer viaje a Occidente", en J. J. Justel, J. P. Vita y J. A. Zamora (eds.), Las culturas del Próximo Oriente Antiguo y su expansión mediterránea: 615-651. Zaragoza.

- (2009): "La Égersis de Melqart. Hipótesis sobre una teología solar cananea", Complutum 20, 2: 95-120.

- (2010): "El Carambolo y la construcción de la arqueología tartésica. Medio siglo de historiografía", en M. L. de la Bandera y E. Ferrer (coords.), El Carambolo. 50 años de un tesoro: 99-148. Secretariado de Publicaciones de la Universidad de Sevilla, Sevilla.

ESCACENA, J. L. e IZQUIERDO, R. (2001): "Oriente en Occidente: arquitectura civil y religiosa en un 'barrio fenicio' de la Caura tartésica”, D. Ruiz y S. Celestino (eds.), Arquitectura oriental y orientalizante en la Península Ibérica. CEPO-CSIC, Madrid.

FERNÁNDEZ, A. y RODRÍGUEZ, A. (2007): Tartessos desvelado. Almuzara, Córdoba.

GALE, N. H. (1991): “Copper oxhide ingots: their origin and their place in the Bronce Age metals trade in the Mediterranean", en N. H. Gale (ed.), Bronze Age trade in the Mediterranean (Studies in Mediterranean Archaeology Vol. XC): 197-239. Jonsered. 
GESTOSO, G. N. (2007): "El barco naufragado en Ulu Burun y el intercambio de bienes en el Mediterráneo oriental", DavarLogos 7.1: 19-32.

GÓMEZ PEÑA, A. (e. p.): "Historiografía y metodología taurodérmica protohistórica", Anales de Arqueología Cordobesa 23.

GRACIA, F. y MUNILLA, G. (2004): Protohistoria. Pueblos y culturas en el Mediteráneo entre los siglos XIV y II a. C. Edicions Universitat de Barcelona, Barcelona.

INSTITUT DU MONDE ARABE (2007): La Méditerranée des Phéniciens: de Tyr à Carthage. Institut du Monde Arabe, Paris.

IZQUIERDO, R. (1998): "La cabaña circular en el mundo tartésico. Consideraciones sobre su uso como indicador étnico", Zephyrus LI: 277-288.

IZQUIERDO, R. y ESCACENA, J. L. (1998): “Sobre el Carambolo: <<La Trompeta de Argantonio >>", Archivo Español de Arqueología 71: 29-36.

JAMES, P. (1993): Siglos de oscuridad: desafio a la cronología tradicional del mundo antiguo. Crítica, Barcelona.

KARAGEORGHIS, V. y PAPASAVVAS, G. (2001): "A bronze ingot-bearer from Cyprus", Oxford Journal of Archaeology 20, 4: 339-354.

KENNA, V. E. G. (1967): “The seal use of Cyprus in the Bronze Age, II", Bulletin de correspondance hellénique 91, 2: 552-577.

KNAPP, A. B. (2008): Prehistoric and Protohistoric Cyprus: identity, insularity and connectivity. Oxford University Press, Oxford.

LAGARCE, J. y LAGARCE, E. (1997): "Les lingots "en peau de boeuf", objets de comerce et symboles idéologiques dans le monde méditerranéen", REPPAL X: 73-97.

LÓPEZ PARDO, F. (2006): La torre de las almas: un recorrido por los mitos y creencias del mundo fenicio y orientalizante a través del monumento de Pozo Moro. Universidad Complutense de Madrid, Madrid.

MAIER, J. (2003): "El lingote en rama chipriota o de piel de toro: símbolo divino de la antigua Iberia", en A. García-Baquero y P. Romero (eds.), Fiestas de toros y sociedad: 85-106. Fundación Real Maestranza de Caballería de Sevilla y Universidad de Sevilla, Sevilla.
MALUQUER DE MOTES, J. (1954): "Pueblos celtas", en R. Menéndez Pidal (dir.), Historia de España, I-3. España primitiva. La historia prerromana: 3-194. Espasa-Calpe, Madrid.

MARÍN, M. C. (2006): "De dioses, pieles y lingotes", Habis 37: 35-54.

MUHLY, J. D.; WHEELER, T. S. y MADDIN, R. (1977): "The Cape Gelidonya Shipwreck and the Bronze Age Metals Trade in the Eastern Mediterranean", Journal of Field Archaeology IV, 3: 353-362.

NIBBI, A. (1987): Ancient Egyptian pot bellows and the oxhide ingot shape. Oxford, DE Publications.

PULAK, C. (1988): "The Bronze Age Shipwreck at Ulu Burun, Turkey: 1985 Campaign”, American Journal of Archaeology 92, 1: 1-37.

ROOS, A. M.; SCHULZ, H. D. y ARTEAGA, O. (1995): "El problema del "Lacus Ligustinus": investigaciones geoarqueológicas en torno a las marismas del Bajo Guadalquivir", Tartessos: 25 años después, 1968-1993, Jerez de la Frontera: 99-135. Jerez de la Frontera.

SCHAEFFER, C. F.-A. (1964): "La XVIe Campagne de fouilles de la Mission Archéologique Française à Enkomi-Alasia, en Chypre", Syria LXI: 179-181.

SCHAEFFER, C. F.-A. (1971): "Les peuples de la mer et leurs santuaires a Enkomi-Alasia aux XIIe-XIe s. av. n. è.”, en C. F. A. Schaeffer (dir.), Alasia I, Tome IV: 505-573. Paris.

VAN DER TOORN, K.; BECKING, B. y VAN DER HORST, P. W. (1999): Dictionary of Deities and Demons in the Bible. Koninklijke Brill NV, Leiden.

VIDAL, J. (2003): Las aldeas de Ugarit. Según los archivos del Bronce Reciente (s. XIV-XII a.n.e.), Universidad Autónoma de Barcelona, Tesis Doctoral publicada electrónicamente en http://www.tdx.cat/ TDX-0701104-171120.

ZAMORA, J. A. (2006): "Les utilisations de l'alphabet lors du II $^{\mathrm{e}}$ millénaire av. J.C. et le développement de l'épigraphie alphabétique: una approche à travers la documentation ougaritique en dehors des tablettes (II)", en G. del Olmo Lete, L. Feliu y A. Millet (eds.), Studies Presented to Joaquin Sanmartin on the Occasion of His 65th Birthday (Aula Orientalis Supplementa 22): 491528. Ausa, Barcelona. 